\title{
Sinorhizobium fredii HH103 cgs Mutants Are Unable to Nodulate Determinate- and Indeterminate Nodule-Forming Legumes and Overproduce an Altered EPS
}

\author{
Juan C. Crespo-Rivas, ${ }^{1}$ Isabel Margaret, ${ }^{1}$ Ángeles Hidalgo, ${ }^{1}$ Ana M. Buendía-Clavería, ${ }^{1}$ \\ Francisco J. Ollero, ${ }^{1}$ Francisco J. López-Baena, ${ }^{1}$ Piedad del Socorro Murdoch, ${ }^{2}$ \\ Miguel A. Rodríguez-Carvajal, ${ }^{3}$ M. Eugenia Soria-Díaz, ${ }^{3,4}$ María Reguera, ${ }^{5}$ Javier Lloret, ${ }^{5}$ \\ David P. Sumpton, ${ }^{6}$ Jackie A. Mosely, ${ }^{7}$ Jane E. Thomas-Oates, ${ }^{6}$ Anton A. N. van Brussel, ${ }^{8}$ \\ Antonio Gil-Serrano, ${ }^{3}$ Jose M. Vinardell, ${ }^{1}$ and Jose E. Ruiz-Sainz ${ }^{1}$ \\ ${ }^{1}$ Departamento de Microbiología and ${ }^{2}$ Departamento de Bioquímica y Biología Molecular, Facultad de Biología, Universidad \\ de Sevilla, Avda. Reina Mercedes 6, C.P. 41012, Sevilla, Spain; ${ }^{3}$ Departamento de Química Orgánica, Facultad de Química, \\ Universidad de Sevilla, Apdo. 553, 41071-Sevilla, Spain; ${ }^{4}$ Servicio de Espectrometría de Masas, Centro de Investigación \\ Tecnológica e Investigación (CITIUS), Universidad de Sevilla, Avda. Reina Mercedes 4, C.P. 41012, Sevilla, Spain; \\ ${ }^{5}$ Departamento de Biología, Facultad de Ciencias, Universidad Autónoma de Madrid, Darwin 2, 28049-Madrid, Spain; \\ ${ }^{6}$ Department of Chemistry, University of York, Heslington, York, YO10 5DD, U.K.; ${ }^{7}$ Department of Chemistry, University \\ of Durham, University Science Labs, South Road, Durham, DH1 3LE, U.K.; ${ }^{8}$ Institute of Biology, Leiden University, \\ Wassenaarseweg 64, 2333AL Leiden, The Netherlands
}

Submitted 31 July 2008. Accepted 20 January 2009.

Sinorhizobium fredii HH103 produces cyclic $\beta$ glucans (CG) composed of 18 to 24 glucose residues without or with 1phosphoglycerol as the only substituent. The $S$. fredii HH103-Rif ${ }^{r}$ cgs gene (formerly known as $n d v B$ ) was sequenced and mutated with the lacZ-gentamicin resistance cassette. Mutant SVQ562 did not produce CG, was immobile, and grew more slowly in the hypoosmotic GYM medium, but its survival in distilled water was equal to that of HH103-Rif ${ }^{r}$. Lipopolysaccharides and $K$-antigen polysaccharides produced by SVQ562 were not apparently altered. SVQ562 overproduced exopolysaccharides (EPS) and its exo $A$ gene was transcribed at higher levels than in HH103Rif $^{r}$. In GYM medium, the EPS produced by SVQ562 was of higher molecular weight and carried higher levels of substituents than that produced by HH103-Rif ${ }^{r}$. The expression of the SVQ562 cgs::lacZ fusion was influenced by the $\mathbf{p H}$ and the osmolarity of the growth medium. The $S$. fredii $\mathrm{cgs}$ mutants SVQ561 (carrying cgs:: $\Omega$ ) and SVQ562 only formed pseudonodules on Glycine max (determinate nodules) and on Glycyrrhiza uralensis (indeterminate nodules). Although nodulation factors were detected in SVQ561 cultures, none of the cgs mutants induced any macroscopic response in Vigna unguiculata roots. Thus, the nodulation process induced by $S$. fredii cgs mutants is aborted at earlier stages in $V$. unguiculata than in Glycine max.

Nucleotide and amino acid sequence data is available in the EMBL database under accession number EU622805.

Corresponding author: José E. Ruiz Sainz; Telephone: +34-954557121; Fax: +34-954557830; E-mail: rsainz@us.es

* The $e$-Xtra logo stands for "electronic extra" and indicates that one supplemental table and two supplemental figures are published online.
Rhizobia are soil $\alpha$-proteobacteria able to establish symbiotic associations with many leguminous plants. This symbiosis leads to the formation of nodules on roots of leguminous plants where the bacteria fix nitrogen. Nodule development requires the exchange of symbiotic signals between the two partners (Gage 2004, Jones et al. 2007). Plant flavonoids and bacterial lipochitooligosaccharides (also called Nod factors or LCO) are two well-known signals acting at the very early stages of nodule formation (Gage 2004).

In addition to Nod factors, different rhizobial surface polysaccharides are required for successful nodulation, during which they might act as signal molecules or could prevent plant defense reactions (Becker and Pühler 1998; Breedveld and Miller 1998; Fraysse et al. 2003; Mathis et al. 2005). Exopolysaccharides (EPS), lipopolysaccharides (LPS), capsular polysaccharides (KPS or K-antigens), and cyclic $\beta$-glucans (CG) are the main rhizobial polysaccharides investigated for their roles in nodulation (Fraysse et al. 2003; Parada et al. 2006). The importance of each particular polysaccharide in the nodulation process varies according to the type of nodule (determinate or indeterminate) that each particular legume is able to develop. For instance, EPS is required for the formation of nitrogen-fixing nodules on plants forming indeterminate nodules, such as Medicago sativa (alfalfa), but apparently it is dispensable in plants that form determinate nodules, such as Glycine max (soybean). In contrast, the symbiotic impairment of rhizobial mutants affected in LPS production appears to be more severe in determinate-nodule forming legumes than in those forming indeterminate nodules (Fraysse et al. 2003; Gage 2004).

Rhizobial mutants unable to form CG are severely impaired in their ability to nodulate determinate and indeterminate noduleforming legumes (Bhagwat et al. 1992; Breedveld and Miller 1998; D'Antuono et al. 2005; Fraysse et al. 2003; Geremia et al. 1987). In Sinohizobium meliloti, two genes, $n d v A$ and $n d v B$, 
are necessary for CG production (Breedveld and Miller 1998). The $n d v A$ gene is involved in CG transport while $n d v B$ (renamed cgs [cyclic glucan synthase]) is responsible for the biosynthesis of CG. $M$. sativa and G. max plants inoculated with rhizobial mutants unable to produce CG only form ineffective pseudonodules. Bacteroids cannot be isolated from alfalfa pseudonodules, which contain a small number of infection threads that abort at an early stage (Breedveld and Miller 1998; Dickstein et al. 1988). In soybean, however, cgs-like mutants of Bradyrhizobium japonicum form ineffective but bacteroid-containing nodules (Bhagwat and Keister 1995). cDNA array technology has been used to compare the transcriptome profiles of Lotus japonicus roots inoculated with a Mesorhizobium loti cgs mutant. The expression of $L$. japonicus genes associated with the development of a fully functional nodule was significantly affected in plants inoculated with the cgs mutant (D'Antuono et al. 2008).

CG are important not only for the symbiotic relationship between rhizobia and legumes but also for the microbial capacity to develop phytopathogenic interactions (Jones et al. 2007). Frequently, mutants of phytopathogenic bacterial strains (such as Agrobacterium tumefaciens and Xanthomonas campestris) unable to produce CG are also impaired in their capacity to develop plant diseases (Breedveld and Miller 1994, 1998; Rigano et al. 2007). The requirement for CG for bacterial pathogenic capacity has also been demonstrated in Brucella abortus, a cattle pathogen that can also infect humans (Arellano-Reynoso et al. 2005; Ugalde 1999). S. meliloti cgs mutants are severely impaired for motility and attachment and invasion of alfalfa roots, so that nitrogen-fixing nodules are not formed (Dylan et al. 1990b). In spite of the dramatic effects observed in bacterial mutants unable to form CG, studies using $S$. meliloti pseudorevertants indicated that these polymers, by themselves, might not be strictly required for the successful interaction of symbiotic bacteria with their eukaryotic hosts. Pseudorevertants selected for restoration of motility showed enhanced attachment capacity to alfalfa roots but were only slightly restored symbiotically. On the other hand, pseudorevertants that have regained nodulation capacity showed little or no attachment capability, indicating that the level of attachment capacity exhibited by the wild-type strain is not strictly required for the invasion of alfalfa roots. Neither motile nor symbiotic revertants regained the capacity to produce CG, which indicates that this polymer is not strictly required for nodule development, even though $S$. meliloti cgs mutants only form pseudonodules that do not fix nitrogen (Dylan et al. 1990b). Mutants unable to produce CG also show alterations in a variety of cell-surface properties when grown in media of low osmolarity. These properties include i) a loss of motility with reduced numbers of flagella, ii) increased resistance to particular bacteriophages, iii) increased sensitivity to some antibiotics, iv) increased production of EPS, and v) modified cell-surface protein composition (Breedveld and Miller 1998). Thus, the symbiotic impairment observed in $c g s$ mutants might be due to a dramatic alteration in the bacterial surface properties.

CG produced by A. tumefaciens, all biovars of Rhizobium leguminosarum, $S$. meliloti, and $S$. fredii $\mathrm{HH} 303$ only contain glucosyl residues that are solely linked by $\beta-(1,2)$ glycosidic bonds. The Xanthomonas CG has 16 glucosyl residues, and contains one $(1,6)$ glycosidic bond and one $\alpha$ linkage (Amemura and Cabrera-Crespo 1986). R. leguminosarum CG are not substituted while those produced by A. tumefaciens, S. meliloti, and $S$. fredii $\mathrm{HH} 303$ carry sn-1-phosphoglycerol substituents (Breedveld and Miller 1994). Bradyrhizobium japonicum, another soybean symbiont, also requires $\mathrm{CG}$ for effective nodulation of soybean roots (Bhagwat and Keister 1995). This bacterium, however, forms a different CG, in which glucosyl residues are linked by $\beta-(1,3)$ - and $\beta$-(1,6)-linkages (Inon de Iannino and Ugalde 1993).

The nucleotide sequence of the $S$. fredii $\operatorname{cgs}(n d v B)$ gene is not available in databases and it is not clear whether, in all cases, $S$. fredii cgs mutants are unable to form nitrogen-fixing nodules with soybean plants. S. fredii Rf19, an $n d v B:: \operatorname{Tn} 5$ mutant derivative of $S$. fredii $\mathrm{HH} 303$, induced ineffective pseudonodules on soybean (G. max cv. Williams) and Vigna unguiculata cv. California Black-eye (Bhagwat et al. 1992). Another report showed, however, that this mutant was able to form nitrogen-fixing nodules with the American soybean cv. McCall and the Asiatic cv. Peking (Inon de Iannino et al. 1996), and an earlier report described that $S$. fredii USDA191 mutants unable to produce EPS and CG induced some functional nodules on G. max cv. Peking (Ko and Gayda 1990). These discrepancies, and the fact that $S$. fredii strains show marked cultivar-strain specificity, prompted us to investigate the symbiotic capacity of $c g s$ mutants of $S$. fredii $\mathrm{HH} 103$ with different soybean cultivars, including those used in the above-mentioned reports. The structure of the CG produced by $S$. fredii $\mathrm{HH} 103$ was also determined. $S$. fredii HH103 was isolated from a Chinese soil sample (Dowdle and Bohlool 1985) and was able to form nitrogen-fixing nodules with Asiatic and American soybean cultivars (Buendía-Clavería et al. 1989; Dowdle and Bohlool 1985).

\section{RESULTS}

\section{Structural characterization \\ of the CG of S. fredii HH103.}

S. fredii HH103 cells were treated with hot water-phenol (a treatment that allows the isolation of rhizobial LPS and periplasmic $\mathrm{CG}$ ) and the aqueous phase was submitted to dialysis, enzyme treatments, and size-exclusion chromatography (SEC). CG were located in a low molecular-weight fraction mixed with the KPS. Subsequent SEC on Biogel P6 allowed the isolation of periplasmic $\mathrm{CG}$, which were submitted to structural analysis. Monosaccharide composition analysis by gas-liquid chromatography (GLC) of trimethylsilyl methyl glycosides showed that only glucose and its absolute configuration was determined as D. Methylation analysis identified only 1,2,5-tri$O$-acetyl-1-deutero-3,4,6-tri- $O$-methylglucitol, derived from units of $\rightarrow 2$ )-D-Glc $p$. The ${ }^{1} \mathrm{H}$-nuclear magnetic resonance (NMR) spectrum (Supplementary Fig. 1A) is very similar to that reported for anionic cyclic $\beta$-glucans from $S$. meliloti 1021 (Breedveld et al. 1995). Correlation spectroscopy (COSY), ${ }^{1} \mathrm{H}-$ ${ }^{13} \mathrm{C}$ heteronuclear single quantum correlation (HSQC) (Supplementary Fig. 2), and ${ }^{1} \mathrm{H}-{ }^{31} \mathrm{P}$ heteronuclear multiple-bond correlation (HMBC) NMR experiments allowed the assignment of NMR signals (Supplementary Table 1) and the determination of the structure of this polysaccharide. Thus, the COSY spectrum allows the assignment of monosaccharide protons $\mathrm{H}-2$ to $\mathrm{H}-6 \mathrm{a}, \mathrm{b}$ starting from the broad signal of $\mathrm{H}-1$ at $\delta_{\mathrm{H}} 4.9 \mathrm{ppm}$; consequently, the HSQC spectrum allows the assignment of the corresponding ${ }^{13} \mathrm{C}$ signals. The chemical shifts of the anomeric signal $\left(\delta_{\mathrm{H}}=4.9 \mathrm{ppm}, \delta_{\mathrm{C}}=102.2 \mathrm{ppm}\right)$ correspond to $\beta$ Glcp units, and the chemical shift of C-2 (approximately 83 ppm) confirms the linkage position. The HSQC spectrum also shows minor signals for methylene groups at $\delta_{\mathrm{C}} 66.4,63.9$, and $62.2 \mathrm{ppm}$, together with an additional crosspeak at $\delta_{\mathrm{H}}=$ $3.87 \mathrm{ppm}$ and $\delta_{\mathrm{C}}=70.7 \mathrm{ppm}$. These sets of signals correspond to a phosphoplycerol residue linked to some of the glucose units via $O-6$ and the corresponding $C-6$ methylenic protons of the substituted monosaccharide residue. The presence of a phosphate group was confirmed from a ${ }^{31} \mathrm{P} N M R$ spectrum, which shows a signal at $\delta_{\mathrm{P}} 0.9 \mathrm{ppm}$. In addition, the ${ }^{1} \mathrm{H}-{ }^{31} \mathrm{P}$ HMBC experiment correlates the phosphorus signal with the methylene signals at $\delta_{\mathrm{H}}=4.15$ and $4.05 \mathrm{ppm}(\mathrm{H}-6 \mathrm{a}$ and $\mathrm{H}-6 \mathrm{~b}$ 
of a 6-O-substituted glucose) and 3.91 and $3.84 \mathrm{ppm}(\mathrm{H}-1 \mathrm{a}$ and $\mathrm{H}-1 \mathrm{~b}$ of a glycerol unit), which agrees with a glucose unit bearing a phosphoglycerol residue at $O-6$. We can conclude that the structure of this polysaccharide consists of units of $\rightarrow 2)-\beta-D-G l c p-(1 \rightarrow$, partially substituted with glycerol-1phosphate at the C-6 position of some of the glucose units, and it is similar to that found in other Rhizobium spp. (Batley et al. 1987; Breedveld et al. 1995). The ratio of substituted to unsubstituted units (1:7) was estimated from the relative areas of $\mathrm{H}-$ 6 crosspeaks in HSQC spectrum. Other possible substituents, such as succinyl groups, were not found.
Negative-ion mode matrix-assisted laser desorption ionization time-of-flight (MALDI-ToF) mass spectrometry (using the linear ToF mode) was used to determine the degree of polymerization (DP) of the cyclic $\beta$-glucans (Fig. 1A). The peaks can be assigned as deprotonated molecules having DP values between 20 and 23 glucose units, with the major components bearing three phosphoglycerol substituents, although there is also evidence for the presence of molecular species carrying four substituents (Fig. 1A, m/z 4383 and 4407). Dephosphorylation of $\mathrm{CG}$ isolated from HH103-Rif ${ }^{\mathrm{r}}$ (rifampicin-resistant) cells with $1 \mathrm{M} \mathrm{NaOH}\left(100^{\circ} \mathrm{C}, 4 \mathrm{~h}\right)$ yielded a fraction com-

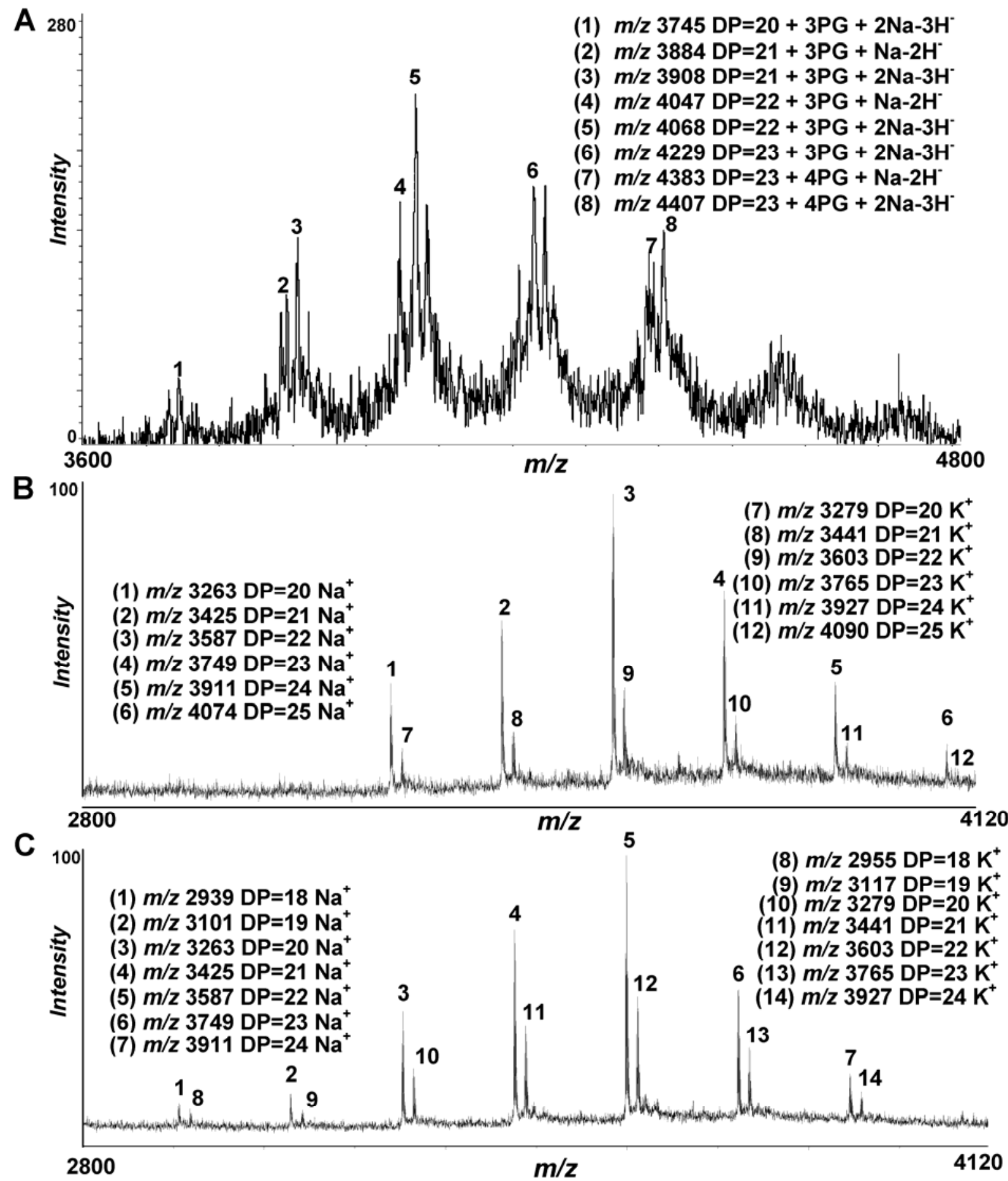

Fig. 1. Matrix-assisted laser desorption ionization time-of-flight analysis of fractions containing the cyclic glucans isolated from A, cells, negative-mode spectrum; B, chemically dephosphorylated periplasmic cyclic glucan, positive-mode spectrum; and C, culture medium of $S$. fredii HH103, positive-mode spectrum. $\mathrm{DP}=$ degree of polymerization; $\mathrm{PG}=$ phosphoglycerol. 
posed of neutral cyclic $\beta$-glucans. The positive-ion MALDI reflectron mode ToF mass spectrum of dephosphorylated $\mathrm{CG}$ is shown in Figure 1B. It allows the identification of species with DP ranging from 20 to 25 glucose units.

Extracellular CG were isolated from culture media by precipitation with ethanol and further purification by SEC (Gil Serrano et al. 1993). The positive-ion mode MALDI reflectron mode ToF mass spectrum (Fig. 1C) of the glucans obtained is very similar to that of the dephosphorylated periplasmic $\mathrm{CG}$, and indicates that the secreted CG isolated do not bear phosphorylated substituents. The set of peaks separated by $162 \mathrm{~m} / z$, units indicates species with DP between 18 and 24 glucose units.

\section{Isolation of the cgs gene of $S$. fredii $\mathrm{HH} 103$.}

Although $c g s$ mutants of $S$. fredii $\mathrm{HH} 303$ have been isolated and studied (Bhagwat et al. 1992; Inon de Iannino et al. 1996), the nucleotide sequence of the $S$. fredii $\operatorname{cgs}(n d v B)$ gene is not available. Thus, to isolate the $c g s$ gene of $S$. fredii $\mathrm{HH} 103$, primers $c g s-\mathrm{F}$ and $c g s$ - $\mathrm{R}$ were designed from the coding sequence of the $n d v B$ gene of $S$. meliloti 1021 (accession number AL591793). Using $S$. fredii HH103 genomic DNA as a template, primers $c g s-\mathrm{F}$ and $c g s$ - R led to the polymerase chain reaction (PCR) amplification of a 2.3-kb fragment whose partial sequencing revealed that it had a high level of identity $(87 \%)$ with the $n d v B$ gene from $S$. meliloti 1021 . From this HH103 sequence, a new pair of primers, called $c g s \mathrm{HH}-\mathrm{F}$ and $c g s \mathrm{HH}-$ $\mathrm{R}$, was designed and used to amplify a 1,230-bp internal fragment of the $S$. fredii HH103 cgs gene. Then, 1,200 clones of a genomic library of $S$. fredii $\mathrm{HH} 103$ were screened for positive PCR amplification with primers $c g s \mathrm{HH}-\mathrm{F}$ and $c g s \mathrm{HH}-\mathrm{R}$, resulting in the identification of cosmid pMUS909.

Hybridization analysis of cosmid pMUS909, using the 1,230-bp HH103 cgs internal fragment as a probe, led us to sequence a 13,293-bp segment (accession number EU622805) which covered the complete $S$. fredii HH103 cgs gene (between positions 2,610 and 11,237). This gene encodes a predicted protein of 2,875 residues, with a molecular weight of $320.6 \mathrm{kDa}$, that is 90 and $89 \%$ identical to the S. meliloti 1021 NdvB protein and the $S$. medicae WSM419 glycosyl transferase 36, respectively (accession nos. CAC47865 and ABR61979). High levels of identity were also found with the Cgs proteins of other rhizobia such as R. etli CFN42 (69\%, ABC92741), R. leguminosarum bv. viciae 3841 (68\%, CAK10127), M. loti MAFF303099 (57\%, BAB53905), and the ChvB protein of A. tumefaciens C58 (67\%, AAL43711).
No significant homologies were found between the $S$. fredii $\mathrm{HH} 103 \mathrm{Cgs}$ protein and those involved in B. japonicum CG production.

In addition to $\operatorname{cgs}$, the $S$. fredii $\mathrm{HH} 103$ segment sequenced contains three other complete and one partial open reading frame (ORF) (Fig. 2). The homologies of the predicted encoded products of the different ORF found in the sequenced fragment are summarized in Table 1. The cgs gene is flanked by two ORF showing the same polarity. An ORF (positions 1,374 to 2,267 ) homologous to $S M c 04882$, a putative transcriptional regulator of the LysR family, is located upstream of cgs (and in the same frame as this gene) and its deduced encoded product is 91 and $90 \%$ identical to the corresponding proteins from $S$. meliloti and $S$. medicae, respectively. An ORF (positions 11,429 to 12,592 ) situated downstream of $c g s$ is homologous to S. meliloti SMc04381 (80\% identity) and $S$. medicae ( $79 \%$ identity), whose deduced encoded proteins are putative glucan succinyl transferases.

At the $5^{\prime}$ terminus of the sequenced fragment $(1,299$ to 1$)$, there is an incomplete ORF homologous to S. meliloti 1021 SMc04383 which encodes a hypothetical protein of unknown function. The nucleotide homology of the whole $S$. frediisequenced fragment with that of S. meliloti 1021 (85 to $86 \%$ identity) extends between positions 1 and 2,262 and 2,441 and 12,582 in the former, and 204,156 and 201,895 and 201,722 and 191,630 in the latter (AL591793). Thus, the homologous zones between these two rhizobia covered four of the five ORF located in the $S$. fredii $\mathrm{HH} 103$-sequenced fragment, from SMc04383 to SMc04381. Downstream of SMc04381, the S. fredii-sequenced fragment did not show significant homology to $S$. meliloti sequences. Instead, the sequenced fragment from position 12,649 to the end was $75 \%$ identical to a segment of the $R$. leguminosarum bv. viciae 3841 chromosome fragment (accession number AM236080) that contains a putative ORF (RL2635) encoding a lysine exporter family protein (RhtB/LysE). The corresponding $S$. fredii $\mathrm{HH} 103 \mathrm{ORF}$, here called lysE, extends between positions 13,262 and 12,630 and it codes for a predicted protein that is 75\% identical to RL2365 and 38\% identical to putative $S$. meliloti and $S$. medicae RhtB proteins, whose chromosomal encoding ORF are located approximately $440 \mathrm{~kb}$ away from the $c g s$ gene. The transcriptional direction of lysE and $S M c 04383$ is opposite to that of cgs.

The $S$. meliloti 1021 genetic organization of the $n d v$ genes ( $n d v B-S m c 043381-S m c 03901-n d v A$ ) is not conserved in $S$. fredii $\mathrm{HH} 103$ because of the presence of lysE just after
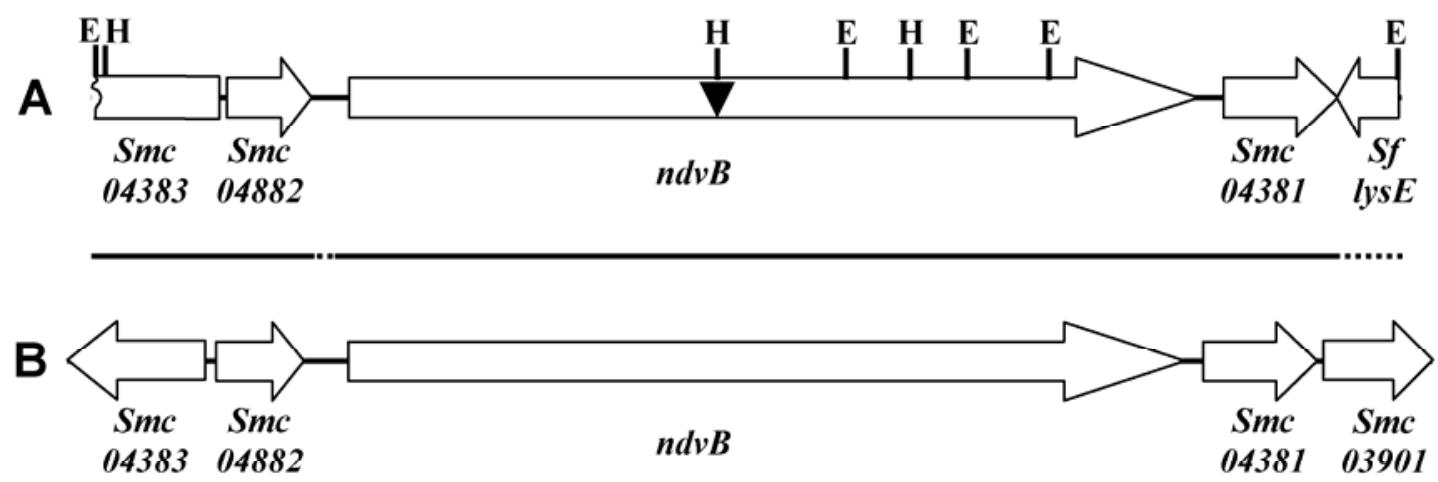

\section{$1 \mathbf{k b}$}

Fig. 2. Genetic organization of the cgs region of A, Sinorhizobium fredii HH103 (accession number EU622805) and B, S. meliloti 1021 (a segment of 13,850 bp between positions 204,297 and 190,447 of the sequence available at the accession number AL591791). The line drawn between the two nucleotide segments represents the presence (continuous) or absence (dotted) of homology between them. The black inverted triangle indicates the position (3,736 of the cgs coding sequence) at which either the $\Omega$ interposon or the lacZ-Gm ${ }^{\mathrm{r}}$ cassette have been inserted to generate mutants SVQ561 and SVQ562 respectively. $\mathrm{E}=$ EcoRI and $\mathrm{H}=$ HindIII. 
Smc04381. Oligonucleotide primers homologous to the $3^{\prime}$ ends of the $\operatorname{cgs}(n d v B)$ and $l y s E$ genes amplified a band showing the expected size (approximately $2.1 \mathrm{~kb}$ ), regardless of whether plasmid pMUS909 or total genomic DNA from HH103 was used as the template (data not shown). Thus, the differences observed between S. meliloti 1021 and S. fredii HH103 are not due to DNA reorganizations in cosmid pMUS909. The same pair of primers also amplified the $2.1-\mathrm{kb}$ DNA band when genomic DNA from $S$. fredii strains USDA192 and USDA205 were used as DNA templates. Thus, this $S$. fredii $\mathrm{HH} 103$ genetic organization (cgs and lysE are closely located) also appears in other $S$. fredii strains.

\section{Isolation and characterization of $S$. fredii $\mathrm{HH103} \mathrm{cgs}$ mutants.}

A cgs mutant (named SVQ562) of $S$. fredii HH103 was generated by inserting the lacZ-Gm ${ }^{\mathrm{r}}$ (gentamycin-resistant) cassette into the $\operatorname{cgs}$ coding sequence. SVQ562 was analyzed for the production of different surface polysaccharides. As expected, CG were not detected in the cellular fraction of mutant SVQ562 using ${ }^{1} \mathrm{H}-\mathrm{NMR}$ analyses (Fig. 3) or in supernatants of SVQ562 cultures (Fig. 4). The K-antigen KPS produced by SVQ562 appears to be identical to that produced by the wildtype strain (Fig. 3), because the ${ }^{1} \mathrm{H}-\mathrm{NMR}$ spectrum corresponding to the KPS produced by the mutant was identical to that previously described for the KPS of S. fredii HH103 (GilSerrano et al. 1999). The cgs mutation did not apparently affect bacterial LPS because $S$. fredii HH103-Rif ${ }^{\mathrm{r}}$ and SVQ562 showed the same LPS electrophoretic profile and the same pattern of LPS bands recognized by the monoclonal antibody NB6-228.22 (data not shown). This monoclonal antibody specifically recognizes the LPS of $S$. fredii $\mathrm{HH} 103$ (BuendíaClavería et al. 2003).

Mobility in hypoosmotic GYM medium (Dylan et al. 1990a) was examined as described below. The SVQ562 mutant did not show mobility in comparison with the parental strain $\mathrm{HH} 103$ and the presence of $100 \mathrm{mM} \mathrm{NaCl}$ in GYM media did not restore the mobility of the cgs mutant (Fig. 5B and C). Moreover, the parental strain showed lower mobility in GYM supplemented with $\mathrm{NaCl}$ than in GYM medium.

Mutant SVQ562 was also examined for the production of EPS. On solid yeast extract-mannitol agar (YMA), SVQ562 was more mucous than HH103-Rif ${ }^{r}$ (Fig. 5A). In liquid YM broth (YMB) medium, the amount of EPS recovered with a glass rod from SVQ562 culture supernatants treated with two volumes of acetone was much higher than that collected from HH103-Rif ${ }^{r}$ (Table 2). In the hypoosmotic GYM medium, EPS was not recoverable with a glass rod either from HH103-Rif ${ }^{\mathrm{r}}$ cultures or from SVQ562 although, in both cases, the addition of acetone provoked the formation of a fibroid material. The addition of $100 \mathrm{mM} \mathrm{NaCl}$ to GYM medium allowed the production of large (rod-recoverable) quantities of EPS by SVQ562 cultures and a slight increase in EPS production by HH103-Rif ${ }^{\mathrm{r}}$ cultures.

However, EPS was recovered from the extracellular medium of all HH103-Rif ${ }^{\mathrm{r}}$ and SVQ562 cultures when culture supernatants were subjected to a fivefold concentration process, followed by the addition of three volumes of ethanol (discussed below). Under these conditions, ${ }^{1} \mathrm{H}-\mathrm{NMR}$ spectra corresponding to the EPS present in the supernatants of $S$. fredii HH103Rif $^{\mathrm{r}}$ cultures were quite similar regardless of whether the bacteria were grown in liquid YM, GYM, or GYM supplemented with $100 \mathrm{mM} \mathrm{NaCl}$ (Fig. 6). ${ }^{1} \mathrm{H}-\mathrm{NMR}$ spectra of EPS produced by HH103-Rif ${ }^{\mathrm{r}}$ and SVQ562 in YMB cultures were almost identical (Fig. 6C). However, the ${ }^{1} \mathrm{H}-\mathrm{NMR}$ spectra of EPS produced by SVQ562 in GYM and GYM + $100 \mathrm{mM}$ $\mathrm{NaCl}$ indicated that the EPS produced by the mutant bears a higher level of substitution (assigned as acetate and pyruvate substituents) than that produced by the parental strain HH103$\mathrm{Rif}^{\mathrm{r}}$, based on the increase in relative areas of signals at approxi-

Table 1. Proteins encoded by the Sinorhizobium fredii HH103-sequenced fragment, (accession number EU622805)

\begin{tabular}{|c|c|c|c|}
\hline Gene position & Protein $^{a}$ & Putative function & Identity $^{\mathbf{b}}$ \\
\hline $1,299-1^{\mathrm{c}}$ & $\mathrm{SMc} 04383(432)^{\mathrm{d}}$ & Conserved hypothetical protein, unknown function & $\begin{array}{l}\text { 90\% SMc04383 S. meliloti } 1021 \\
\text { (466; CAC47867) } \\
\text { 86\% DUF1338 S. medicae WSM419 } \\
\text { (472; ABR61981) } \\
\text { 74\% DUF1338 Ochrobactrum anthropi ATCC } \\
\text { 49188 (488; ABS14177) }\end{array}$ \\
\hline $1,374-2,267$ & 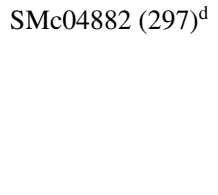 & Probable transcription regulator protein, LysR family & $\begin{array}{l}\text { 91\% SMc04882 S. meliloti } 1021 \\
\quad(297 ; \text { CAC47866) } \\
90 \% \text { Smed_3156 S. medicae WSM419 } \\
\quad(297 ; \text { ABR61980) } \\
\text { 72\% BRA0906 Brucella suis } 1330 \\
\quad(310 ; \text { AAN34078) }\end{array}$ \\
\hline $2,610-11,237$ & NdvB (2875) & $\beta$ - $(1,2)$-Glucan production-associated transmembrane protein & $\begin{array}{l}90 \% \text { NdvB S. meliloti } 1021 \text { (2,832; CAC47865) } \\
89 \% \text { Glycosyltransferase } 36 \text { S. medicae WSM419 } \\
\quad(2870 ; \text { ABR61979) } \\
69 \% \text { NdvB R. etli CFN42 (2,825; ABC } 92741)\end{array}$ \\
\hline $11,429-12,592$ & $\operatorname{SMc04381(387)^{\mathrm {d}}}$ & Hypothetical transmembrane protein, glucan succinyl transferase & $\begin{array}{l}\text { 80\% SMc04381 S. meliloti } 1021 \\
\text { (385; CAC47864) } \\
\text { 79\% Smed_3156 S. medicae WSM419 } \\
\quad(385 ; \text { ABR61978) } \\
\text { 54\%RHE_CH03998 R. etli CFN42 } \\
\quad(412 ; \text { ABC } 92742)\end{array}$ \\
\hline $13,262-12,630$ & LysE (210) & Lysine exporter family protein (RhtB/LysE) & $\begin{array}{l}\text { 75\% RL2635 R. leguminosarum bv. viciae } 3841 \\
\text { (203; CAK08123) } \\
\text { 75\% SIAM614_25766 Stappia aggregata IAM } \\
\text { 12614 (222; EAV41606) } \\
\text { 67\% BamMC406DRAFT_5884 Burkholderia } \\
\text { ambifaria MC40-6 (290; EAV51594) }\end{array}$ \\
\hline
\end{tabular}

\footnotetext{
a Number of residues of each protein is shown in parentheses.

${ }^{b}$ Number of residues and the accession number are shown in parentheses.

${ }^{\mathrm{c}}$ Stop codon of this open reading frame is not found in the sequenced fragment.

${ }^{\mathrm{d}}$ As annotated for the highest identical protein found in the databases.
} 
mately 2 and 1.5 ppm (Fig. 6A and B). The molecular weight of the EPS produced by HH103-Rif ${ }^{\mathrm{r}}$ and SVQ562 was estimated by SEC high-pressure liquid chromatography (HPLC) (discussed below). Most of the EPS produced by HH103-Rif ${ }^{\text {r }}$ appeared in a region that corresponds to a polysaccharide with a molecular weight of approximately 50 to $60 \mathrm{kDa}$ (Fig. 7 , region $\mathrm{B})$. The size exclusion chromatogram of the EPS produced by SVQ562 showed two peaks, one in region $\mathrm{B}$, the

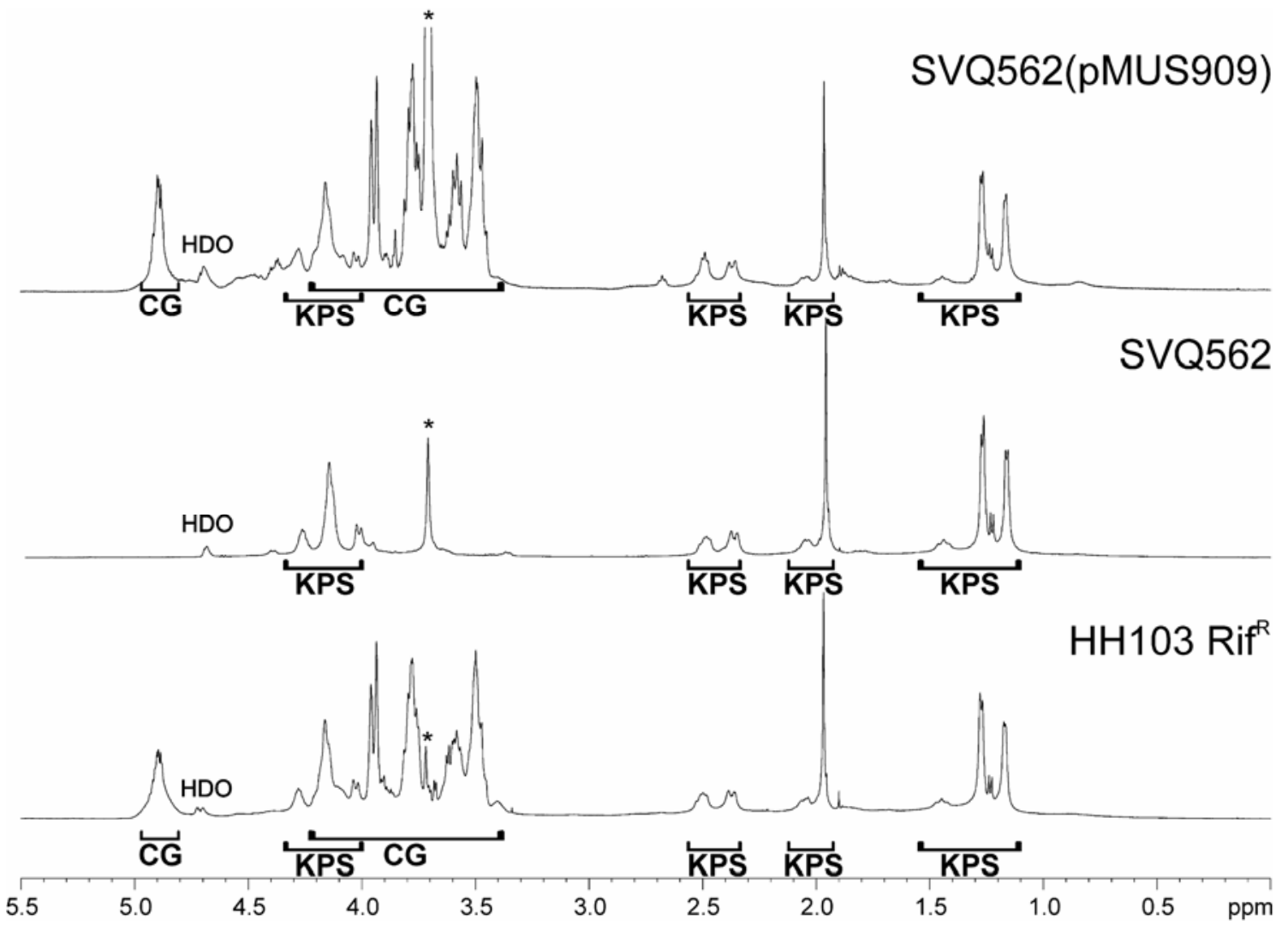

Fig. 3. ${ }^{1} \mathrm{H}$ nuclear magnetic resonance spectra of phenol-water extracts isolated from Sinorhizobium fredii HH103-Rif ${ }^{\mathrm{r}}$, SVQ562, and SVQ562 (pMUS909). Signals corresponding to capsular polysaccharides (KPS) and cyclic glucans (CG) are indicated. Asterisks show signals from Tris buffer.
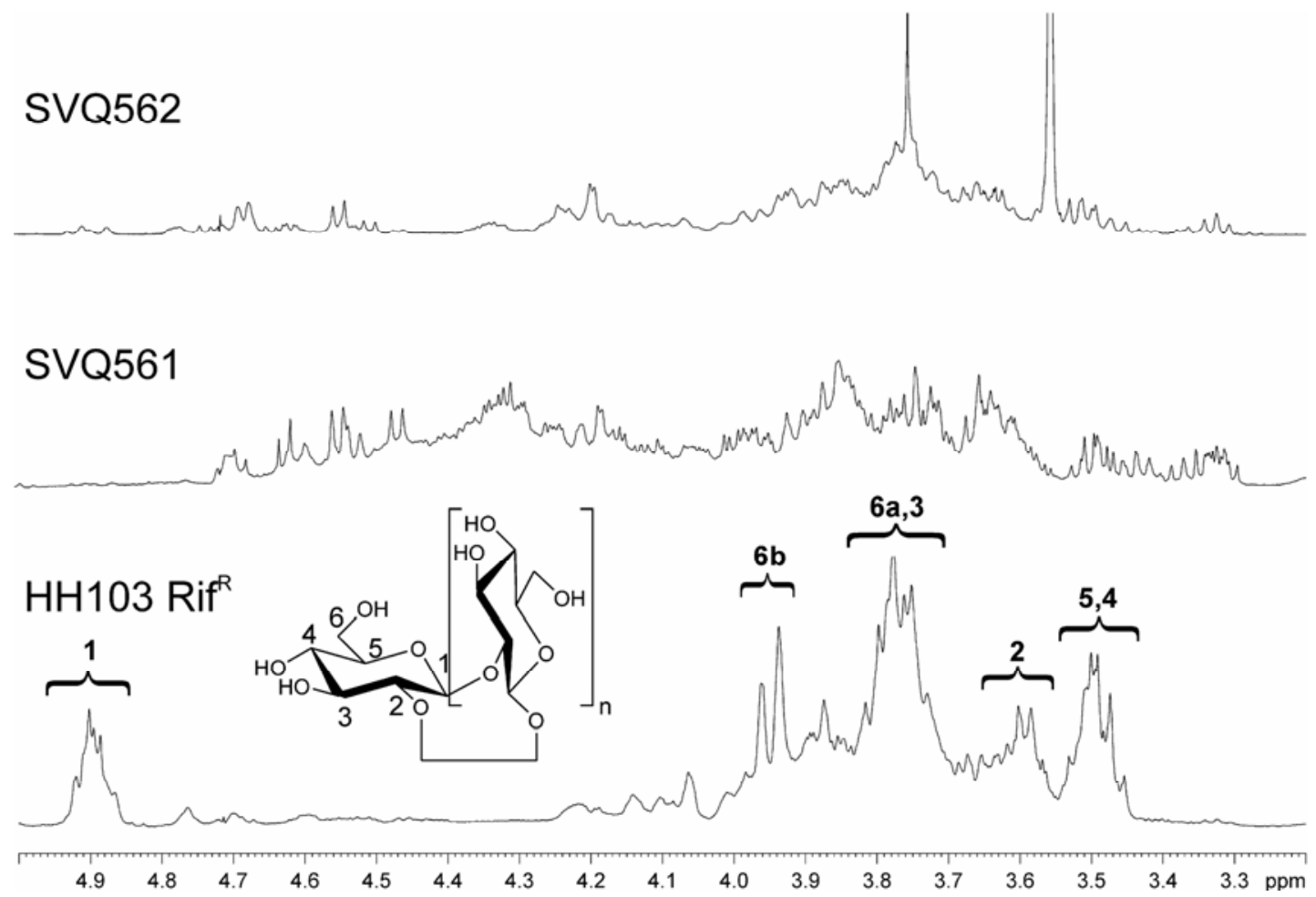

Fig. 4. ${ }^{1} \mathrm{H}$ nuclear magnetic resonance $(500 \mathrm{MHz})$ of fractions isolated from culture supernatants of Sinorhizobium fredii HH103-Rif ${ }^{\mathrm{r}}$, SVQ561, and SVQ562. Signals corresponding to cyclic glucans were found only in the wild-type strain HH103-Rif ${ }^{\mathrm{r}}$. 
other in the region corresponding to at least 2,000 kDa (Fig. 7, region $\mathrm{A}$ ).

CG have been described as playing a defensive role against hypoosmotic conditions (Breedveld and Miller 1998). We have examined the growth rates of strains HH103-Rif ${ }^{\mathrm{r}}$ and SVQ562 in the three different media mentioned above. HH103-Rif ${ }^{\mathrm{r}}$ and SVQ562 showed similar generation times in YMB $(204 \pm 8$ and $228 \pm 12 \mathrm{~min}$, respectively) and in GYM media supplemented with $\mathrm{NaCl}(216 \pm 8$ and $222 \pm 9$ min, respectively). In the hypoosmotic GYM medium, however, the generation time exhibited by the $\operatorname{cgs}$ mutant (approximately $324 \pm 19 \mathrm{~min}$ ) was clearly higher than that of $S$. fredii HH103 (240 \pm 10 min). This difference in the speed with which bacteria grew in the different media assayed did not result in significant differences
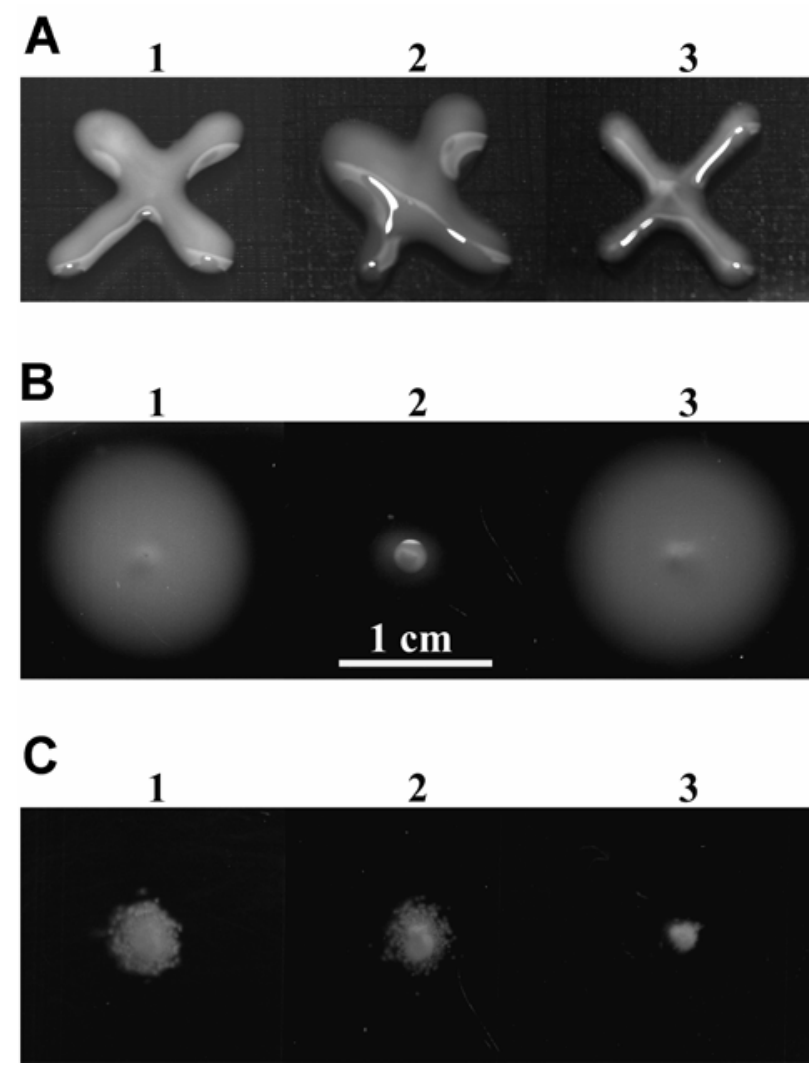

Fig. 5. Appearance of Sinorhizobium fredii HH103-Rif ${ }^{\mathrm{r}}$ and its $c g s$ derivative SVQ562 growing on A, yeast extract-mannitol agar medium and $\mathbf{B}$, their mobility on GYM (Dylan et al. 1990a) and C, GYM supplemented with $100 \mathrm{mM} \mathrm{NaCl}$. Column 1, HH103-Rif ${ }^{\mathrm{r}}$; column 2, SVQ562; column 3, SVQ562 (pMUS909).

Table 2. Exopolysaccharides produced by Sinorhizobium fredii HH103Rif $^{\mathrm{r}}$ and SVQ562 $2^{\mathrm{a}}$

\begin{tabular}{|c|c|c|c|}
\hline Media & Bacterial strain & $\begin{array}{c}\text { Cells/ml } / \mathbf{m l} \\
\left(\times 10^{8}\right)\end{array}$ & $\begin{array}{l}\text { Exopolysaccharide } \\
(\mathrm{mg}) \text { released into } \\
100 \mathrm{ml} \text { of medium }\end{array}$ \\
\hline \multirow[t]{2}{*}{ YMB } & HH103-Rif ${ }^{r}$ & 2.7 & $6.3 \pm 0.8$ \\
\hline & SVQ562 & 7.0 & $17.7 \pm 1.2$ \\
\hline \multirow[t]{2}{*}{ GYM } & HH103-Rif ${ }^{r}$ & 1.5 & 0.0 \\
\hline & SVQ562 & 1.3 & 0.0 \\
\hline \multirow[t]{2}{*}{$\mathrm{GYM}+\mathrm{NaCl}$} & HH103-Rif ${ }^{r}$ & 2.1 & $0.6 \pm 0.1$ \\
\hline & SVQ562 & 2.2 & $19.8 \pm 1.0$ \\
\hline
\end{tabular}

${ }^{a}$ In yeast extract-mannitol broth (YMB), GYM (Dylan et al. 1990a), and GYM supplemented with $100 \mathrm{mM} \mathrm{NaCl}$. Numbers are mean values of three different experiments. Bacterial cultures were gown for 7 days before exopolysaccharides released into the cells milieu were precipitated by adding two volumes of acetone. in the total bacterial population reached by the cultures at stationary phase, which was approximately $10^{8}$ cells $\mathrm{ml}^{-1}$. We have also investigated whether the absence of $\mathrm{CG}$ affects the bacterial capacity to survive under severe hypoosmotic conditions. For this purpose, HH103-Rif ${ }^{\mathrm{r}}$ and SVQ562 were resuspended in distilled water (at a cell density of 3 to $8 \times 10^{5}$ cells $\mathrm{ml}^{-1}$ ) and incubated at $28^{\circ} \mathrm{C}$. After incubation for $72 \mathrm{~h}$, the number of viable cells of SVQ562 $\left(10^{5}\right.$ cells ml-1) was similar to that of strain HH103-Rif ${ }^{\mathrm{r}}\left(0.8 \times 10^{5}\right.$ cells ml $\left.^{-1}\right)$. HH103-Rif ${ }^{\mathrm{r}}$

\section{A}

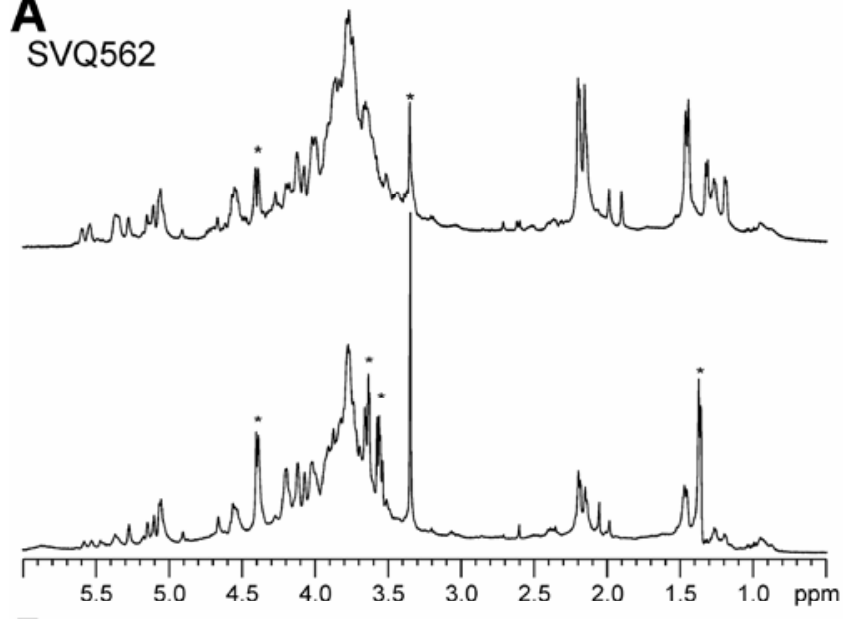

B

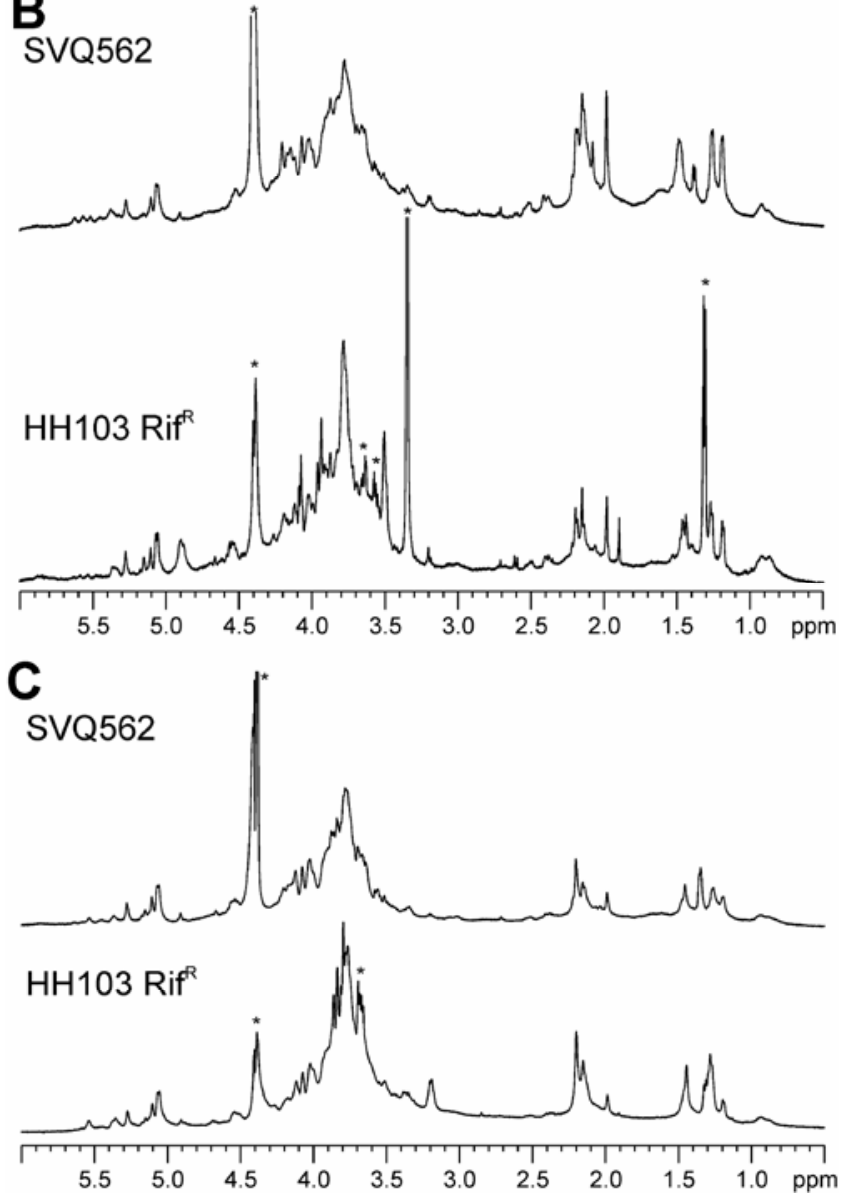

Fig. 6. ${ }^{1} \mathrm{H}$ nuclear magnetic resonance $(500 \mathrm{MHz} ; 333 \mathrm{~K})$ of exopolysaccharide produced by Sinorhizobium fredii HH103-Rif ${ }^{\mathrm{r}}$ and SVQ562 cultures grown in A, the hypoosmotic GYM (Dylan et al. 1990a) medium; B, GYM supplemented with $100 \mathrm{mM} \mathrm{NaCl}$; and $\mathbf{C}$, yeast extractmannitol broth medium. Asterisks indicate signals of HDO (4.40 ppm) and glycerol. 
and SVQ562 were able to grow in YMB media containing $0.07 \%$ (wt/vol) of the detergent sodium dodecyl sulfate (SDS). However, the cgs mutant was delayed in reaching the stationary growth phase: approximately 72 and $96 \mathrm{~h}$ (absence and presence of SDS, respectively) for HH103-Rif ${ }^{\mathrm{r}}$ and 96 and 168 $\mathrm{h}$ (absence and presence of SDS, respectively) for mutant SVQ562.

\section{S. fredii HH103 cgs expression is affected}

\section{by the presence of flavonoids, $\mathbf{p H}$, and osmolarity.}

S. fredii SVQ562 (it carries a cgs::lacZ-Gm ${ }^{\mathrm{r}}$ fusion) cultures grown in the presence and absence of the flavonoids genistein and coumestrol were assayed for $\beta$-galactosidase activity. Three independent experiments, each composed of two replicates, showed that LacZ activity of SVQ562 cultures in the presence of genistein (202 \pm 35 Miller units) or coumestrol $(185 \pm 39)$ was significantly lower $(\alpha=5 \%)$ than that in the absence of flavonoids $(252 \pm 23)$.

The effect of the $\mathrm{pH}$ at which bacteria were grown on $\operatorname{cgs}$ expression was investigated by culturing mutant SVQ562 in acidic- ( $\mathrm{pH}$ 6.0), neutral- ( $\mathrm{pH} 7.0)$, and alkaline-buffered ( $\mathrm{pH}$ 8.0) YMB media. Nonbuffered YMB media, with a $\mathrm{pH}$ value of 7.0 at the time of inoculation, was also included. Three independent experiments, each composed of two replicates, showed that the $\beta$-galactosidase activity of SVQ562 cultures grown at $\mathrm{pH} 8$ (146 \pm 25 Miller units) was significantly lower $(\alpha=5 \%)$ than that of cultures at $\mathrm{pH} 6(315 \pm 73)$ and $\mathrm{pH} 7$ $(237 \pm 28)$. The $\mathrm{pH}$ of cultures in nonbuffered media shifted from an initial $\mathrm{pH}$ value of 7.0 to 6.75 at the time $\beta$-galactosidase assays were carried out, and their $\beta$-galactosidase activity was $257 \pm 24$. Three independent experiments, each composed of at least three replicates, showed that $\beta$-galactosidase activity of SVQ562 in YMB and GYM media $(258 \pm 77$ and $291 \pm 62$, respectively) were similar but significantly higher than in GYM media supplemented with $100 \mathrm{mM} \mathrm{NaCl}(185 \pm 43)$.

\section{Effect of the cgs mutation}

\section{on the $S$. fredii HH103 exoA gene expression.}

Mutant SVQ562 overproduces EPS, thus forming colonies that are more mucous than those of the parental strain $\mathrm{HH} 103$ Rif $^{\mathrm{r}}$. Four independent real-time reverse-transcription polymerase chain reaction ( $r t$-RT-PCR) experiments were carried out to investigate whether the exoA gene, encoding a glucosyltransferase that adds the first glucosyl residue to the nascent EPS repeating unit, showed higher expression in the cgs mutant (SVQ562) than in the wild-type strain HH103-Rif ${ }^{\mathrm{r}}$. Expression of the exoA genes was clearly higher (7.4- \pm 1.3 -fold) in mutant SVQ562 than in HH103-Rif ${ }^{\text {r }}$

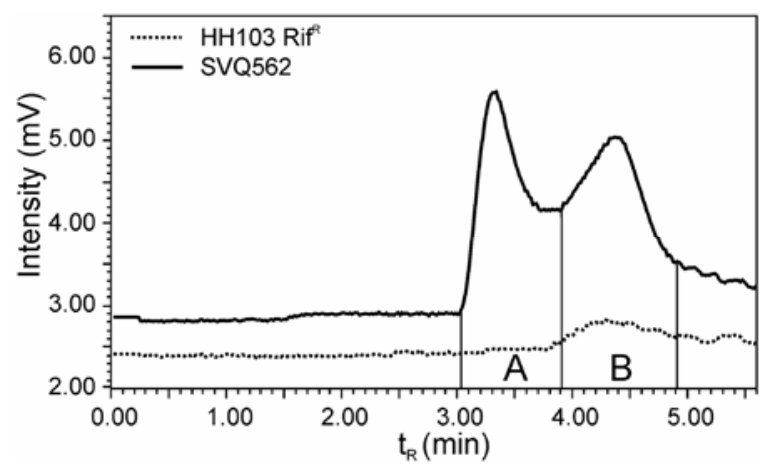

Fig. 7. Size-exclusion chromatogram of exopolysaccharide produced by HH103-Rif ${ }^{\mathrm{r}}$ (dotted line) and SVQ562 (solid line). Region A corresponds to molecular weights equal to or higher than $2,000 \mathrm{kDa}$ (void volume). Region B corresponds to polysaccharides with molecular weights of approximately 50 to $60 \mathrm{kDa}$.

\section{Symbiotic characterization of cgs mutants} of $S$. fredii $\mathrm{HH} 103$.

Previous studies describing the symbiotic phenotype of an $S$. fredii $\mathrm{HH} 303$ cgs mutant reported contradictory results (Bhagwat et al. 1992; Inon de Iannino et al. 1996). Because of this, in addition to SVQ562, we have included in our studies a second independent $S$. fredii $\mathrm{HH} 103$ cgs mutant as a way to reinforce the conclusions derived from plant test results. This mutant, called SVQ561, was produced by inserting the $\Omega$ cassette into the cgs gene of $S$. fredii HH103-Rif ${ }^{\mathrm{r}}$. As expected, ${ }^{1} \mathrm{H}-\mathrm{NMR}$ spectra showed that supernatants of SVQ561 cultures were devoid of CG (Fig. 4). The symbiotic phenotypes of the $S$. fredii HH103 cgs mutant derivatives (SVQ561 and SVQ562) were investigated with several host plants: G. $\max$ (cvs. McCall, Osumi, Peking, and Williams), V. unguiculata cv. Bisbee Red (cowpea), and Glycyrrhiza uralensis. These three legumes form nitrogen-fixing nodules with $S$. fredii HH103-Rif ${ }^{\mathrm{r}}$, although $G$. uralensis plants inoculated with strain HH103-Rif ${ }^{\mathrm{r}}$ show very high variability in the number of nodules formed. Mutants SVQ561 and SVQ562 were unable to induce the formation of nitrogen-fixing nodules in any of the legumes tested, regardless of whether they formed determinate (Glycine max and V. unguiculata) or indeterminate (Glycyrrhiza uralensis) nodules.

G. uralensis inoculated with SVQ561 and SVQ562 only formed pseudonodules devoid of bacteria. However, the two determinate nodule-forming legumes tested showed differences in their plant responses to inoculation with the $\operatorname{cgs}$ mutants: Glycine max plants induced the formation of pseudonodules while no macroscopic root responses were observed in $V$. unguiculata roots. This observation prompted us to investigate whether the lack of bacterial CG could somehow affect the exchange of early symbiotic signals between the $S$. fredii HH103 cgs mutants and V. unguiculata, such as the capacity of $V$. unguiculata flavonoids to activate the transcription of nod genes or the bacterial capacity to produce Nod factors.

We first investigated whether co-inoculation of $V$. unguiculata (cowpea) roots with mutants SVQ295 and SVQ562 results in the formation of nitrogen-fixing nodules occupied by the mutant unable to synthesize CG. SVQ295 is an auxotrophic purL mutant unable to invade soybean roots (it secretes LCO but only pseudonodules are formed) that, in co-inoculation experiments, can complement $S$. fredii SVQ116 (a nodA mutant, unable to produce LCO) to form nitrogen-fixing nodules on soybean plants (Buendía-Clavería et al. 2003). Mutant SVQ562 was chosen for these studies because any nodule formed could be investigated for its $\beta$-galactosidase activity (presence of SVQ562). Cowpea plants inoculated with the co-inoculants SVQ295 (purL mutant) and SVQ562 (cgs mutant) only formed a few pseudonodules, indicating that $\mathrm{CG}$ produced by the purL mutant (which produces a ${ }^{1} \mathrm{H}-$ NMR spectrum identical to that observed for wild-type CG) cannot complement the symbiotic deficiency of mutant SVQ562. Cowpea roots inoculated with the co-inoculants used as a control (SVQ295 and SVQ116) formed nitrogenfixing nodules that were solely occupied by SVQ116, the mutant unable to synthesize LCO.

Plasmid pMP240 was introduced into strains SVQ561 and HH103-Rif ${ }^{\mathrm{r}}$ to investigate whether flavonoids or $G$. $\max$ or $V$. unguiculata root exudates were able to activate the transcription of nodulation genes in the $\operatorname{cgs}$ mutant. Plasmid pMP240 contains the lac $Z$ gene under the control of the $R$. leguminosarum nodA promoter (Spaink et al. 1987). The presence of the flavonoid genistein $(50 \mathrm{nM})$ as well as root exudates of $G$. max or V. unguiculata in HH103-Rif ${ }^{\mathrm{r}}$ (pMP240) and SVQ561 (pMP240) cultures provoked at least an eightfold increase in lacZ activity. Nod factors produced by SVQ561 cultures in the 
presence of the nod gene inducer genistein were also investigated. Nineteen different LCO were detected in the SVQ561 culture grown in the presence of genistein: III(C16:0, MeFuc); III(C16:1); III(C16:1, MeFuc); III(C18:1); III(C18:0, MeFuc); III(C18:1, Fuc); III(C18:1, MeFuc); III(C20:1, MeFuc); IV(C16:0, MeFuc); IV(C16:1); IV(C16:1, MeFuc); IV(C18:1); IV(C18:1, Fuc); IV(C18:1, MeFuc); IV(C18:0, MeFuc); IV(C20:1, MeFuc); V(C16:0, MeFuc); V(C16:1, MeFuc); and $\mathrm{V}(\mathrm{C} 18: 1, \mathrm{MeFuc})$.

Although V. unguiculata roots inoculated with $\operatorname{cgs}$ mutants of $S$. fredii $\mathrm{HH} 103$ did not show macroscopic responses (such as root outgrowths), microscopy studies showed that mutant SVQ561 was indeed able to form nodule primordia on Vigna roots (Fig. 8). One possibility that might explain why these microscopic nodule primordia do not further develop into a macroscopic nodule is that, for whatever reason, the survival of S. fredii HH103 cgs mutants in the rhizosphere of V. unguiculata might be very poor. Liquid samples from $V$. unguiculata plants growing in hydroponic cultures and inoculated with $S$. fredii $\mathrm{HH} 103-$ Rif $^{\mathrm{r}}$ or SVQ561 $\left(10^{6}\right.$ cells/ml of plant nutritive solution) contained similar bacterial populations (approximately $5 \times 10^{6}$ cells ml-1 10 days after inoculation, indicating that the survival of the cgs mutant is not compromised in the rhizosphere of $V$. unguiculata plants.

\section{Complementation of the $S$. fredii $\mathrm{HH} 103$ cgs mutant.}

Cosmid pMUS909 (carrying the complete cgs gene) was transferred by conjugation to mutant SVQ562. SVQ562 transconjugants carrying pMUS909 regained the capacity to produce wild-type $\mathrm{CG}$ in view of the fact that the ${ }^{1} \mathrm{H}-\mathrm{NMR}$ spectrum corresponding to the CG produced by SVQ562 (pMUS909) was identical to that of $S$. fredii $\mathrm{HH} 103-$ Rif $^{\mathrm{r}}$ (Fig. 3).

The presence of pMUS909 in SVQ562 reduced EPS production to a level similar to that observed in the wild-type strain HH103-Rif ${ }^{\mathrm{r}}$ (Fig. 5A) and restored bacterial mobility on GYM medium (Fig. 5B). HH103-Rif ${ }^{\mathrm{r}}$ and SVQ562 (pMUS909) showed similar mobility in GYM supplemented with $100 \mathrm{mM} \mathrm{NaCl}$ (Fig. 5C).

We have previously mentioned that the expression level of the exoA gene was higher (7.4- \pm 1.3 -fold) in mutant SVQ562 than in the parental strain. However, the expression of the exoA gene in SVQ562 carrying pMUS909 was only 50\% (0.49 \pm 0.02) of that in HH103-Rif ${ }^{\mathrm{r}}$.

SVQ562 (pMUS909) was able to induce the formation of nitrogen-fixing nodules in soybean cv. Williams, V. unguiculata, and Glycyrrhiza uralensis. As expected, isolates from nodules were $\mathrm{Gm}^{\mathrm{r}}$ (presence of the lacZ-Gm ${ }^{\mathrm{r}}$ cassette) and tetracycline resistant (presence of cosmid pMUS909).

\section{DISCUSSION}

CG produced by $S$. fredii $\mathrm{HH} 103$ can be detected in the cellular fraction as well as in the cell's milieu. The structure consists of a homopolysaccharide of $\rightarrow 2)-\beta$-D-Glc $p$ - $(1 \rightarrow$ residues, partially substituted with glycerol-1-phosphate at the $C-6$ position of some of the glucose units. Thus, the structure of the CG produced by $S$. fredii $\mathrm{HH} 103$ is nearly identical to that of $S$. meliloti strains, which are phylogenetically closely related to $S$. fredii. The only difference between $S$. fredii $\mathrm{HH} 103 \mathrm{CG}$ and those produced by some $S$. meliloti strains, such as Rm1021 or $102 \mathrm{~F} 34$, is that the former does not carry succinyl substitutions (Breedveld and Miller 1998).

In $S$. meliloti, it has been previously shown that the addition of phosphoglycerol substituents to the cyclic $\beta$-(1,2)-glucans occurs primarily during early and mid-logarithmic growth and it is greatly reduced in stationary cells (Geiger et al. 1991), while neutral cyclic $\beta$-glucan biosynthesis may continue through the stationary phase (Breedveld et al. 1990). These previous results are in accordance with the fact that supernatants of $S$. fredii HH103 cultures grown for 3 days (stationary phase) only contain neutral CG, whereas bacterial cells still contain a mixture of neutral and anionic CG. The fact that the ${ }^{1} \mathrm{H}-\mathrm{NMR}$ spectrum and the MALDI mass spectrum (Figure 1) of extracellular CG are almost identical to that of chemically dephosphorylated cellular CG indicates that the presence of phosphoglycerol substituents is the only difference between the two types of $\mathrm{CG}$.

Although the results of studies of CG produced by another S. fredii strain (called $\mathrm{HH} 303$ ) have been previously reported, to our knowledge, the nucleotide sequence of the $S$. fredii $\operatorname{cgs}$ $(n d v B)$ gene is not available in the databases. We have sequenced the $\operatorname{cgs}$ gene of $S$. fredii $\mathrm{HH} 103$ and showed that its encoded product (Cgs) has a high level of identity to that (NdvB) of S. meliloti and S. medicae. The 13,293-bp fragment sequenced shows the same genetic organization of the two ORF (Smc04383 and Smc04882) upstream of $c g s$ and for that (Smc04381) immediately downstream of cgs. However, the

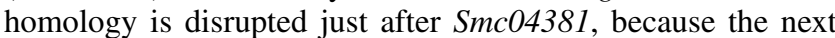
ORF (here called lysE) shows homology to an $S$. meliloti ORF that is situated approximately $440 \mathrm{~kb}$ away from $\operatorname{cgs}$. In $S$. meliloti 1021 , the $n d v B$ and $n d v A$ genes are separated by Smc04381 and Smc03901. In S. fredii HH103, the position of $S m c 03901$ is replaced by lysE, which indicates that the $S$. fredii $\mathrm{HH} 103$ fragment comprising $\operatorname{cgs}(n d v B)$ and $n d v A$ is different from that of $S$. meliloti. This alteration is not specific to strain HH103 because positive PCR amplification is obtained in $S$. fredii USDA192 and USDA205 when primers are designed from the $3^{\prime}$ ends of $c g s$ and $l y s E$. We have not determined the exact position of the $n d v A$ gene but we know that this gene is present in cosmid pMUS909 because PCR experiments (using primers designed from the $S$. meliloti $1021 n d v A$ gene) amplifies a band of the expected size (data not shown). All these results indicate that, in some $S$. fredii strains isolated from different regions of China, the DNA stretch containing the $n d v A$ and $n d v B$ is different from that in S. meliloti 1021 . Although databases suggest that the ORF immediately downstream of $\operatorname{cgs}$ might code for a hypothetical glucan succinyl transferase protein (SMc04381), the enzymatic activity of this gene in $S$. fredii HH103 would be expected to be different, because the presence of succinyl substituents has not been detected in the CG produced by this bacterium.

The $c g s$ mutant SVQ562 constructed in this work is unable to produce $\mathrm{CG}$, has lost its swimming capacity, and grows more slowly in GYM hypoosmotic media, as previously reported for other $\operatorname{cgs}(n d v B)$ rhizobial mutants (Breedveld and

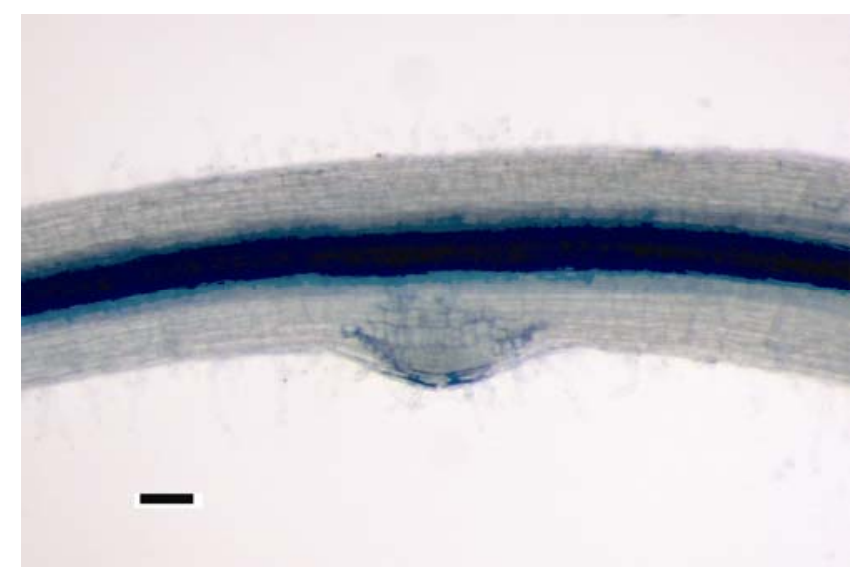

Fig. 8. Nodule primordium formed by mutant SVQ561 on Vigna unguiculata plants. Bar $=0.1 \mathrm{~mm}$. 
Miller 1998). Although the hypoosmotic sensitivity of rhizobial mutants unable to produce CG is well documented (Dylan et al. 1990a) and $S$. meliloti $1021 n d v B$ mutants do not survive in distilled water, our results show that, although SVQ562 grows more slowly in GYM media, its capacity to withstand severe hypoosmotic conditions $(72 \mathrm{~h}$ in distilled water) is no different from that of its wild-type strain. This fact suggests that the symbiotic impairment shown by SVQ562 might not be due to an inability of the mutant to adapt to changes in osmotic conditions.

Rhizobial $\operatorname{cgs}(n d v B)$ mutants show a pleiotropic phenotype, which indicates that the absence of CG provokes other alterations, most probably in the bacterial cell surface. We have searched for possible alterations in the other rhizobial surface polysaccharides that are known to play a role in symbiosis (LPS, KPS, and EPS). Apparently, the $c g s$ mutation in SVQ562 does not cause alterations in the production of LPS or KPS. However, SVQ562 produced more EPS in YMB and $\mathrm{GYM}+\mathrm{NaCl}$ media than the parental strain HH103-Rif ${ }^{\mathrm{r}}$. In YMB medium, the increase in EPS production observed in mutant SVQ562 correlates with the observed higher expression of the exoA gene, which is involved in EPS biosynthesis. In the hypoosmotic GYM medium, the EPS produced by SVQ562 showed higher levels of noncarbohydrate substitutions and its molecular weight reached much higher values. Thus, there are clear differences between the EPS produced by HH103-Rif ${ }^{\mathrm{r}}$ and SVQ562 under hypoosmotic conditions. Transcription of Smc04381, which appears after $\operatorname{cgs}$ and in the same transcriptional direction, was detected in HH103-Rif and SVQ562 (data not shown), indicating that this gene might not be responsible for the differences observed between the EPS produced by HH103-Rif ${ }^{r}$ and SVQ562. The fact that mutation of the cgs gene can also affect the degree of EPS polymerization appears as a striking coincidence with the previous unexplained and intriguing observation that the oligosaccharide repeating unit of the EPS of $S$. meliloti cannot be detected in culture supernatants of $n d v A$ mutants (Stanfield et al. 1988). Thus, all these results indicate that $n d v A$ and $\operatorname{cgs}(n d v B)$ not only influence the amount of EPS produced but also its degree of polymerization. In fact, Becker and associates (1995a) suggested that NdvA might participate in EPS export. Differences in the relative production of high molecular weight EPS depending on the environmental osmolarity has been reported for S. meliloti SU47 but not for A. tumefaciens (Breedveld and Miller 1998; Breedveld et al. 1990).

In the hypoosmotic GYM medium, the EPS produced by SVQ562 carries more substitutions than that produced by HH103-Rif ${ }^{r}$ cultures, indicating that, in this medium, the mutation abolishing CG production also provokes an increase in the degree of EPS substitutions. This increase in EPS substitutions also appears in SVQ562 cultures in GYM supplemented with $100 \mathrm{mM} \mathrm{NaCl}$, indicating that increasing the osmolarity of the growth medium by adding this ionic solute did not restore the wild-type levels of EPS substitution. The $c g s$ mutation does not provoke a clear increase in EPS substitution if the bacteria are grown in YMB medium, which contains large amounts (10 g/liter) of mannitol. Thus, apparently, the composition and osmolarity of the growth medium differentially affect the structural characteristics of the EPS produced by the wild-type strain and its cgs mutant. In $S$. meliloti Rm102F34, however, the $n d v A$ and $n d v B$ mutants produce EPS that is indistinguishable by NMR from that of the wild type (Nagpal et al. 1992).

The symbiotic properties of $S$. fredii $\operatorname{cgs}(n d v B)$ mutants are contradictory. Some reports have shown that soybean cv. Williams and V. unguiculata cv. California Black-eye plants inoculated with a $\operatorname{cgs}$ mutant (Rf19) of $S$. fredii HH303 only form small knot-like structures (pseudonodules) unable to fix nitrogen and devoid of rhizobial cells (Bhagwat et al. 1992). However, other reports have shown that this mutant is able to form nitrogen-fixing nodules with American (McCall) and Asiatic (Peking) soybean cultivars (Inon de Iannino et al. 1996). Here, we show that two independent $c g s$ mutants of another $S$. fredii strain (HH103) only form pseudonodules on American and Asiatic soybean cultivars. Thus, the fact that a $\operatorname{cgs}$ mutant of another $S$. fredii strain (HH303) is able to form nitrogen-fixing nodules on soybean plants appears as an exceptional case in which rhizobial mutants unable to produce $\mathrm{CG}$ are still able to nodulate.

The fact that an S. fredii $\mathrm{HH} 103$ exoA mutant forms nitrogen-fixing nodules on soybean roots (Parada et al. 2006) and that a double cgs exoA mutant only forms pseudonodules (unpublished data) suggests that EPS may not play a relevant role in the bacterial symbiotic interaction with soybean.

In our experimental conditions, $V$. unguiculata roots did not show macroscopic responses to inoculation, although the formation of microscopic nodule primordia could be observed. This failure to produce clearly visible pseudonodules is not due to any incapacity of the $S$. fredii $\mathrm{HH} 103 \mathrm{cgs}$ mutants to produce LCO in the presence of flavonoids or $V$. unguiculata root exudates. These results suggest that the nodulation process induced by $S$. fredii $\mathrm{HH} 103$ cgs mutants is blocked in $V$. unguiculata plants at earlier stages than in soybean. S. fredii cgs mutants only formed ineffective pseudonodules with $G$. uralensis, an indeterminate nodule-forming legume. Thus, we conclude that, as far as we know, mutations abolishing CG production are the most deleterious mutations for symbiosis among those affecting the production of rhizobial surface polysaccharides (EPS, LPS, $\mathrm{KPS}$, and CG) because the bacterial symbiotic capacity is severely impaired regardless of whether the host plant forms determinate or indeterminate nodules. Earlier reports, however, have shown that, apparently, the production of CG is not strictly required by the bacterium to nodulate (Dylan et al. 1990b; Ko and Gayda 1990; Nagpal et al. 1992) because, for instance, spontaneous symbiotic pseudorevertants of $S$. meliloti cgs mutants do not produce CG but have regained the capacity to form nitrogenfixing nodules with alfalfa. It might be possible that the inability to produce CG together with alterations in the EPS produced could account for the symbiotic incapability of cgs mutants. In fact, an $S$. meliloti Rm102F34 cosmid containing exo genes restores the symbiotic capacity of $\mathrm{Rm} 102 \mathrm{~F} 34 n d v A$ or $n d v B$ mutants (Nagpal et al. 1992).

The pleiotropic phenotype of the $S$. fredii SVQ562 mutant is only due to the mutation in the $\operatorname{cgs}$ gene because SVQ562 (pMUS909) produces CG, its mobility is restored, and it effectively nodulates Glycine max, V. unguiculata, and Glycyrrhiza uralensis. SVQ562 produces more EPS in YMB medium than the parental strain HH103-Rif ${ }^{\mathrm{r}}$, but the introduction of cosmid pMUS909 into SVQ562 lowers EPS production to, approximately, that of the wild-type strain.

We have shown that the expression level of the exoA gene was higher (7.4- \pm 1.3 -fold) in mutant SVQ562 than in the parental strain. This overexpression of the exoA gene in SVQ562 disappears in the presence of cosmid pMUS909. The fact that the expression level of the exoA gene in SVQ562 (pMUS909) was only $50 \%$ of that in HH103-Rif ${ }^{\mathrm{r}}$ can be explained as a gene-dosage effect because cosmid pMUS909 (which carries the cgs gene) should be in more than one copy.

Although the addition of purified CG increases nodulation of alfalfa roots inoculated with the wild-type $S$. meliloti 102 F34 strain, the exogenous application of $\mathrm{CG}$ at the time of inoculation with an S. meliloti 102F34 $n d v B$ mutant was ineffective in correcting the symbiotic impairment (Dylan et al. 1990b). We show here that the presence of the co-inoculant SVQ295 (that 
produces LCO and CG) enables an $S$. fredii $\mathrm{HH} 103$ nodA mutant (unable to produce LCO) to effectively nodulate $V$. unguiculata but it does not enhance the ability of mutant SVQ562 to nodulate this legume. Nodules produced by $V$. unguiculata plants inoculated with co-inoculants SVQ116 and SVQ295 were only occupied by the former, indicating that SVQ295 does not invade $V$. unguiculata roots. These results indicate that, although the external addition of purified GC can enhance nodulation induced by wild-type strains, neither the exogenous addition of purified CG (Dylan et al. 1990b) nor the CG produced by the accompanying co-inoculant can complement in trans the cgs coinoculant in nodulating cowpea plants.

The fact that cgs mutants show a pleiotropic phenotype makes it difficult to determine the relative symbiotic importance of each particular phenotypic change observed. Nevertheless, the recent finding that the application of purified $X$. campestris CG to Nicotiana benthamiana leaves provokes the suppression of different plant defense mechanisms (Rigano et al. 2007) clearly indicates that CG, by themselves, play an important role in plant-microbe interactions.

\section{MATERIALS AND METHODS}

\section{Molecular and microbiological techniques.}

Sinorhizobium strains were grown at $28^{\circ} \mathrm{C}$ on TY medium (Beringer 1974), yeast extract/mannitol (YM) medium (Vincent 1970), or GYM medium (Dylan et al. 1990a). Escherichia coli was cultured on Luria-Bertani (LB) medium (Sambrook et al. 1989 ) at $37^{\circ} \mathrm{C}$. When required, the media were supplemented with the appropriate antibiotics as described by Lamrabet and associates (1999). The number of viable cells of liquid cultures was estimated by plate counting. Cell density of liquid cultures was estimated by measuring the absorbance at $600 \mathrm{~nm}$.

Assays for $\beta$-galactosidase activity in liquid bacterial cultures on YMB were carried out $16 \mathrm{~h}$ after induction as described by Vinardell and associates (2004a). At least three independent experiments performed in duplicate were carried out. When necessary, the $\mathrm{pH}$ of the YM medium was buffered to $\mathrm{pH} 6$ with MES $(20 \mathrm{mM})$ or to $\mathrm{pH} 7$ or 8 with HEPES $(20 \mathrm{mM})$.

For mobility assays, GYM medium was solidified with $0.24 \%$ (wt/vol) agar and inoculated (by puncturing) with $3 \mu \mathrm{l}$ of early-exponential phase cultures of $S$. fredii strains. Plates were incubated at $28^{\circ} \mathrm{C}$ for $72 \mathrm{~h}$.

Sensitivity to SDS was studied on YMB supplemented with 0.03 to $0.07 \%$ SDS (wt/vol). For this purpose, late stationaryphase cultures grown in YMB medium were 1,000-fold diluted in YMB containing SDS and incubated in an orbital shaker $(180 \mathrm{rpm})$ at $28^{\circ} \mathrm{C}$. The optical density at $600 \mathrm{~nm}\left(\mathrm{OD}_{600}\right)$ was observed for $96 \mathrm{~h}$ upon inoculation.

Plasmids were transferred from $E$. coli to rhizobia by conjugation as described by Simon (1984). Recombinant DNA techniques were performed according to the general protocols of Sambrook and associates (1989). For hybridization, DNA was blotted onto Amersham (Tokyo) Hybond-N nylon membranes, and the DigDNA method of Roche Diagnostics (Mannheim, Germany) was employed according to the manufacturer's instructions. PCR amplifications were performed as previously described (Vinardell et al. 2004b). For amplifying internal $c g s$ fragments, primer pairs used were $c g s-\mathrm{F}$ (5' TGGGAGCGCAAGC GCGGCAA)/cgs-R (5' CGAACATCGAGCCCGACCA) and $c g s \mathrm{HH}-\mathrm{F}$ (5' GACCCGCTACGAGGTCGAGA)/cgsHH-R (5' CCGGCAATGCGCT CTTCGA). Primers were designed by using the GeneFisher2 utility. The UWGCG program was used for basic DNA sequence analysis and assembly. The National Center for Biotechnology Information ORF-Finder and BLAST programs were used for ORF identification and homology searches, respectively.
In order to generate $\operatorname{cgs}$ mutants of $S$. fredii HH103, we constructed derivatives of pK18mob (Schafer et al. 1994), a suicide vector in rhizobia, carrying an internal fragment of the $\mathrm{HH} 103$ cgs gene (the 2.3-kb fragment amplified with primers $c g s-\mathrm{F}$ and $c g s-\mathrm{R}$ ) interrupted by the $l a c Z:: \mathrm{Gm}^{\mathrm{r}}$ cassette (Becker et al. 1995 b) or the $\Omega$ interposon (Prentki and Krisch 1984) subcloned as a 4.5- or a 2-kb HindIII fragment into the unique HindIII site of the HH103 cgs internal fragment. The plasmids generated, named pMUS868 (cgs:: $\Omega$ ) and pMUS871 (cgs::lacZ$\mathrm{Gm}^{\mathrm{r}}$ ), were individually transferred to HH103-Rif ${ }^{\mathrm{r}}$, and Rif ${ }^{\mathrm{r}}$ spectinomycin-resistant $\mathrm{Km}^{\mathrm{s}}$ (kanamycin-sensitive) or $\mathrm{Rif}^{\mathrm{r}} \mathrm{Gm}^{\mathrm{r}}$ $\mathrm{Km}^{\mathrm{s}}$ transconjugants, respectively, were identified in order to isolate double recombinants in which the wild-type $\operatorname{cgs}$ gene had been substituted by the mutated copy of the gene. Thus, mutants SVQ561 (=HH103-Rif ${ }^{\mathrm{r}} \operatorname{cgs}:: \Omega$ ) and SVQ562 $\left(=\mathrm{HH} 103-\mathrm{Rif}^{\mathrm{r}}\right.$ cgs::lacZ-Gm $\left.{ }^{\mathrm{r}}\right)$ were obtained. In both cases, homogenotization of the mutated version of the $\operatorname{cgs}$ gene was confirmed by DNA-DNA hybridization.

\section{rt-PCR analysis.}

S. fredii strains HH103-Rif ${ }^{\mathrm{r}}$ and SVQ562 were incubated in YMB in an orbital shaker $(180 \mathrm{rpm})$ at $28^{\circ} \mathrm{C}$. When the cultures reached an $\mathrm{OD}_{660}$ of 0.3 , cells were harvested and RNA was extracted by using the RNAprotect Bacteria Reagent and the RNAeasy mini kit (both provided by Qiagen, Basel, Switzerland) following the manufacturer's instructions. Retrotranscription of the RNA was carried out using the Quantitect kit (Qiagen). Quantitative $r t$-RT-PCR were performed in a $20-\mu \mathrm{l}$ final volume containing $1 \mu \mathrm{l}$ of cDNA, $0.6 \mathrm{pmol}$ of each primer, and $10 \mu \mathrm{l}$ of FastStart SYBR Green Master Mix (Roche Diagnostics). PCR was conducted on the iCycler IQ (Bio-Rad Laboratories SA, Marnes La Coquette, France), and the threshold cycles were determined with the iCycler software. Primers used for amplification of a 197-bp internal fragment of the $S$. fredii HH103 exoA gene (accession number AY882558) were rtexoA-F (5'-CGCGCGTCCTTTTCCTTGACA) and rtexoA-R (5'-GGTTTGCATGGCGACGACCA). To normalize the data, a 196-bp internal fragment of the $S$. fredii $\mathrm{HH} 10316 \mathrm{~S}$ rRNA (accession number AY260145) was employed as an internal control in each sample by using primers HH16S-F (5'-GGA TCGGAGACAGGTGCTGCA) and HH16S-R (5'-CGTGTGTAGCCCAG CCCGTA). Three independent experiments performed in triplicate were carried out.

\section{Studies of bacterial polysaccharides.}

For extraction of EPS from liquid cultures, S. fredii strains were grown in $50 \mathrm{ml}$ of the appropriate medium on an orbital shaker $(180 \mathrm{rpm})$ for $96 \mathrm{~h}$ (approximately 5 to $7 \times 10^{9}$ bacteria $\mathrm{ml}^{-1}$ ). When required, the media were supplemented with genistein at a final concentration of $1 \mu \mathrm{g} \mathrm{m}^{-1}$. After centrifugation at $10,000 \times g$ for $10 \mathrm{~min}$, supernatants were mixed with three volumes of acetone and the EPS was recovered with a glass rod, dried at $60^{\circ} \mathrm{C}$ for $3 \mathrm{~h}$, and weighed. To investigate EPS production on solid YM medium, rhizobial strains were grown for $120 \mathrm{~h}$ at $28^{\circ} \mathrm{C}$ followed by $48 \mathrm{~h}$ at room temperature. LPS extraction, separation on SDS polyacrylamide gel electrophoresis, and silver staining were performed as previously described (Buendía-Clavería et al. 2003). Immunostaining procedures and the monoclonal antibody NB6-228.22 were described by Buendía-Clavería and associates (2003).

\section{Isolation of bacterial surface polysaccharides for chemical analyses.}

S. fredii $\mathrm{HH} 103$ or its mutant derivatives were grown in 7 liters of TY liquid medium for 3 days on an orbital shaker (160 $\mathrm{rpm})$ at $28^{\circ} \mathrm{C}$. Early stationary phase cells were harvested by slow-speed centrifugation. 
Isolation of periplasmic $C G$. Bacterial pellets (approximately $4.38 \mathrm{~g}$ ) were washed three times with $0.9 \%$ (wt/vol) $\mathrm{NaCl}$ and freeze dried. The polysaccharide was extracted from the freeze-dried bacterial cells with 1:1 hot phenol-water mixture (100 ml) (Westphal and Jann 1965), and the two phases were separated. The aqueous phase was dialyzed against water, freeze dried, and redissolved in $10 \mathrm{mM} \mathrm{MgSO}_{4}$ and $50 \mathrm{mM}$ Tris- $\mathrm{HCl}$ solution (100 ml, pH 7.0); DNase (1 mg) and RNase (1 mg) were added, and the solution was stirred overnight at $5^{\circ} \mathrm{C}$. Proteinase $\mathrm{K}(2 \mathrm{mg})$ was added, and the solution was shaken for $24 \mathrm{~h}$ at $37^{\circ} \mathrm{C}$, dialyzed, and then freeze dried. The polysaccharide was chromatographed on Sephacryl S-500 (60 by $2.6 \mathrm{~cm}$ ), using $0.05 \mathrm{M}$ EDTA/triethylamine, $\mathrm{pH} 7.0,0.02 \%$ $\mathrm{NaN}_{3}$ as eluent, and carbohydrates were detected using a refractive-index detector and the orcinol-sulfuric acid method on thin-layer chromatography plates. Fractions containing carbohydrates were dialyzed and freeze dried. Chromatography on Biogel P6 $(60$ by $2.6 \mathrm{~cm}$ ) was carried out using $0.02 \mathrm{M}$ $\mathrm{HCOONH}_{4}$ as eluent, and carbohydrates were detected as above.

Isolation of EPS and extracellular CG. Culture supernatant (1.2 liters) was concentrated to $20 \%$ of its original volume and mixed with ethanol (3 vol). The resulting precipitate contained the EPS, which was removed by centrifugation, resuspended, and purified by dialysis. Supernatants were concentrated to $5 \%$ of their original volume, mixed with ethanol (10 vol), and centrifuged to precipitate the low molecular weight fraction that contained CG (Gil Serrano et al. 1993). This fraction was dialyzed against water with a $10-\mathrm{kDa}$ JumboSep device (Pall Corporation, New York) and the diffusate was chromatographed on Sephadex G-25 (30 by $5 \mathrm{~cm}$ ) with water as eluent. Carbohydrates were detected using a refractive-index detector and the orcinol-sulfuric acid method on thin-layer chromatography plates.

\section{Lipo-chitin-oligosaccharide analysis.}

Genistein-induced culture medium (2 liters) was extracted with $n$-butanol (1 liter). The butanol extract was evaporated to dryness under vacuum and the residue was suspended in $10 \mathrm{ml}$ of $50 \%$ acetonitrile (ACN)-water by overnight shaking. Water $(15 \mathrm{ml})$ was added and the crude extract was prepurificated by solid-phase extraction on a C18 cartridge (6 ml of SPE per gram of Resprep; Restek Corp., Bellefonte, PA, U.S.A.). The SPE cartridge was previously conditioned with $\mathrm{ACN}(10 \mathrm{ml})$ and 10 $\mathrm{ml}$ of $20 \%$ ACN-water. Then, the crude extract was passed through the cartridge. Salts and polar compounds were eluted by passage of $5 \mathrm{ml}$ of $20 \%$ ACN-water. Nod factors were eluted using methanol $(10 \mathrm{ml})$. This fraction was concentrated, freeze dried, and dissolved in $1 \mathrm{ml}$ of $50 \% \mathrm{ACN}$-water to be analyzed by HPLC-dual mass spectrometry (MS/MS).

Chromatographic separation was performed using a PerkinElmer Series 200 HPLC system (Wellesley, MA, U.S.A.) coupled to an Applied Biosystem QTRAP LC-MS/MS system (Foster City, CA, U.S.A.) consisting of a quadrupole-linear ion trap mass spectrometer equipped with an electrospray ion source.

HPLC analyses were performed on a 250-by-2.1-mm Tracer Spherisorb ODS2 C18 reversed-phase column with a particle size of $5 \mu \mathrm{m}$ (Teknokroma, Barcelona, Spain). The flow rate

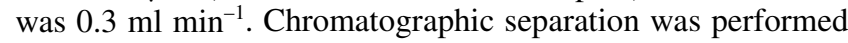
using a binary gradient consisting of water and ACN. Both components contained $0.1 \%$ formic acid ( $\mathrm{vol} / \mathrm{vol})$. The elution profile was isocratic for $5 \mathrm{~min}$ with $30 \% \mathrm{ACN}$, linear for 30 min up to $100 \%$ ACN, and isocratic for 2 min. Mass spectrometric detection was performed in the positive-ion mode after electrospray ionization. For HPLC-MS/MS analyses, the mass spectrometer was set to the following optimized tune parame- ters: curtain gas, 35 psi; ionspray voltage, $5,500 \mathrm{~V}$; source temperature, $300^{\circ} \mathrm{C}$; source gas, $20 \mathrm{psi}$; declustering potential, 50 $\mathrm{V}$; and entrance potential, $10 \mathrm{~V}$. Collision-induced dissociation (CID) was performed with the following collision energy: 35 V. Only those precursor ions with $\mathrm{m} / \mathrm{z}$ between 800 and 1,600 and intensities higher than 1,000 cps were selected for CIDMS/MS analysis.

\section{Monosaccharide analysis.}

Monosaccharides were identified on GLC-MS separation of their trimethylsilylated methyl glycosides obtained as described (Gil-Serrano et al. 1998). The absolute configuration of monosaccharides was assigned following GLC-MS analysis of their trimethylsilylated $(S)$ - and $(R, S)$-2-butyl glycosides, which were prepared as described (Gerwig et al. 1978). Derivatives of authentic standard monosaccharides were prepared for comparison.

GLC-MS was performed on a Micromass AutoSpec-Q instrument fitted with an OV-1 column $(25 \mathrm{~m}$ by $0.25 \mathrm{~mm})$. The temperature program for separating the trimethylsilylated methyl glycosides was isothermal at $150^{\circ} \mathrm{C}$ for $2 \mathrm{~min}$ followed by a $10^{\circ} \mathrm{C} \mathrm{min}{ }^{-1}$ gradient up to $250^{\circ} \mathrm{C}$. The temperature program for separating the trimethylsilylated 2-butyl glycosides was isothermal at $130^{\circ} \mathrm{C}$ for $3 \mathrm{~min}$ followed by a $3^{\circ} \mathrm{C} \mathrm{min} \mathrm{m}^{-1}$ gradient up to $150^{\circ} \mathrm{C}$ and then a new $10^{\circ} \mathrm{C} \mathrm{min}{ }^{-1}$ gradient up to $250^{\circ} \mathrm{C}$. In all cases, the ionization potential was $70 \mathrm{eV}$ and spectra were recorded in low-resolution mode.

\section{Methylation analysis.}

The vacuum-desiccated polysaccharide sample was methylated by the method of Ciucanu and Costello (2003). Then, the sample was hydrolyzed, reduced with $\mathrm{NaB}^{2} \mathrm{H}_{4}$, and acetylated as described (Kim et al. 2006). GLC-MS was performed on a Micromass AutoSpec-Q instrument fitted with an OV-1 column ( $25 \mathrm{~m}$ by $0.25 \mathrm{~mm}$ ). The temperature program for separating the partially methylated alditol acetates was isothermal at $120^{\circ} \mathrm{C}$ for $1 \mathrm{~min}$ followed by an $8^{\circ} \mathrm{C} \mathrm{min}^{-1}$ gradient up to $250^{\circ} \mathrm{C}$. The ionization potential was $70 \mathrm{eV}$ and spectra were recorded in low resolution mode.

\section{Molecular weight determination.}

Molecular weight estimation was made by SEC in an HPLC system. Separation was carried out on a $\mu$ Bondagel E-Linear (Waters Corp., Milford, MA, U.S.A.). As the mobile phase, 0.1 $\mathrm{M} \mathrm{NaNO}_{3}$ was used with an operating temperature of $50^{\circ} \mathrm{C}$, a flow rate of $0.5 \mathrm{ml} \mathrm{min}^{-1}$, and an injection volume of $20 \mu \mathrm{l}$. The polymers were detected by refractive index using a 410 Differential Refractrometer (Waters Corp.). Solutions (5 mg $\mathrm{ml}^{-1}$ ) of standard dextrans of 39.1, 70, 110, 252, and 2,000 $\mathrm{kDa}$ (Sigma-Aldrich, St. Louis) were used to estimate the molecular weights of the eluting peaks according to the method of Granath and Kvist (1967).

Samples containing EPS (4 to $7 \mathrm{mg}$ ) were resuspended in $0.1 \mathrm{M} \mathrm{NaNO}_{3}$ (1 to $2 \mathrm{ml}$ ) and, after stirring overnight, centrifuged at 4,000 rpm. Supernatant was further microfiltered and analyzed by SEC-HPLC.

\section{NMR spectroscopy.}

Samples were deuterium exchanged several times by freeze drying from ${ }^{2} \mathrm{H}_{2} \mathrm{O}$, and then examined in solution $(5 \mathrm{mg}$ per $750 \mu \mathrm{l}$ ) in $99.98 \%{ }^{2} \mathrm{H}_{2} \mathrm{O}$. Spectra were recorded at $303 \mathrm{~K}$ on a Bruker AV500 spectrometer operating at $500.13 \mathrm{MHz}\left({ }^{1} \mathrm{H}\right)$, 125.75 $\mathrm{MHz}\left({ }^{13} \mathrm{C}\right)$, and $202.46 \mathrm{MHz}\left({ }^{31} \mathrm{P}\right)$. Chemical shifts are given in ppm, using the $\mathrm{H}^{2} \mathrm{HO}$ signal $(4.75 \mathrm{ppm})\left({ }^{1} \mathrm{H}\right)$, external dimethylsulfoxide (39.5 ppm) $\left({ }^{13} \mathrm{C}\right)$, and external phosphoric acid $\left(0 \mathrm{ppm},{ }^{31} \mathrm{P}\right)$ as references. The two-dimensional (2D) homonuclear COSY was performed using the Bruker standard 
pulse sequence. A data matrix of 256-by-1K points was used to digitize a spectral width of $4,845 \mathrm{~Hz} ; 32$ scans were used per increment. The 2D heteronuclear one-bond proton-carbon correlation experiment was registered in the ${ }^{1} \mathrm{H}$-detection mode via HSQC. A data matrix of 256 -by- $1 \mathrm{~K}$ points was used to digitize a spectral width of 4,845 and $22,522 \mathrm{~Hz}$ in $\mathrm{F}_{2}$ and $\mathrm{F}_{1}$, respectively; 64 scans were used per increment. ${ }^{13} \mathrm{C}$ decoupling was achieved by the GARP scheme. Squared-cosinebell functions were applied in both dimensions, and zero-filling was used to expand the data to $1 \mathrm{~K}$ by $1 \mathrm{~K}$. The ${ }^{1} \mathrm{H}-{ }^{31} \mathrm{P}$ HMBC experiment was performed using the Bruker standard sequence with 256 increments of $1 \mathrm{~K}$ real points to digitize a spectral width of 4,807 by $20,243 \mathrm{~Hz}$; eight scans were acquired per increment with a delay of $33 \mathrm{~ms}$ for evolution of longrange couplings.

\section{MALDI-MS.}

Positive-ion MALDI mass spectrometric data were acquired from the neutral CG on an Applied Biosystems 4700 Proteomics analyzer with ToF/ToF optics (Applied Biosystems, Foster City, CA, U.S.A.), operated in reflectron mode. The 2,5-dihydroxybenzoic acid matrix was prepared as a saturated solution in $50 \%$ ACN, $0.1 \%$ trifluoroacetic acid (TFA), and then diluted $1: 1$ in the same solvent. Sample solutions were mixed with an equal volume of matrix solution and $1 \mu \mathrm{l}$ of the resultant mixture was deposited onto the MALDI target plate and allowed to dry by evaporation. The MALDI source was equipped with a $200-\mathrm{Hz}$ frequency-tripled $\mathrm{Nd}$ :YAG laser operating at a wavelength of $355 \mathrm{~nm}$. Spectra were recorded over the $\mathrm{m} / \mathrm{z}$ range of approximately 2,500 to 4,500 , with a "focus mass" of $\mathrm{m} / \mathrm{z}$ 3,000 , using a total of 2,500 laser shots at an intensity of 5,000 .

Negative-ion MALDI mass spectra of substituted CG were acquired on an Autoflex II ToF/ToF MS (Bruker Daltonik $\mathrm{GmbH}$ ) fitted with a 337-nm nitrogen laser and operated in linear mode, summing a total of 400 laser shots. A $1-\mathrm{mg} / \mathrm{ml}$ solution of sample was mixed on the MALDI target in a $1: 1$ ratio with matrix. The matrix, a $50-\mathrm{mg} / \mathrm{ml}$ solution of 2,5-dihydroxybenzoic acid (Bruker Daltonik GmbH, Barcelona, Spain), was dissolved in 30\% ACN (Sigma, Poole, U.K.), 70\% water $(18 \mathrm{M} \Omega$ ) containing $0.1 \%$ TFA (Sigma). Raw data were processed using the FlexAnalysis (Bruker Daltonik, $3.0 \mathrm{GmbH}$ ) software using the SavitzkyGolay smoothing algorithm.

\section{Plant assays.}

Nodulation assays on Glycine max (L.) Merr. cvs. Williams, McCall, Osumi, and Peking; V. unguiculata, and Glycyrrhiza uralensis were carried out as described by Crespo-Rivas and associates (2007). Germinated seeds were transferred to Leonard jars containing sterilized vermiculite supplemented with Fåhraeus nutrient solution (Vincent 1970). Each plant was inoculated with approximately $10^{8}$ bacteria and then grown for at least 6 weeks with a 16 -h photoperiod at $25^{\circ} \mathrm{C}$ in the light and $18^{\circ} \mathrm{C}$ in the dark. Plant tops were dried at $80^{\circ} \mathrm{C}$ for $48 \mathrm{~h}$ and weighed. Bacterial isolation from surface-sterilized nodules and coinoculation experiments were carried out as described by Buendía-Clavería and associates (2003).

The survival of $S$. fredii HH103-Rif ${ }^{\mathrm{r}}$ and SVQ561 in the presence of $V$. unguiculata (cowpea) roots was estimated as follows: surface-sterilized cowpea seed were germinated and transferred to tubes $(25 \mathrm{~cm}$ high and $3 \mathrm{~cm}$ wide) containing $100 \mathrm{ml}$ of Fåhraeus nutrient solution. Each tube containing one cowpea seedling was inoculated with $10^{8}$ bacteria of $S$. fredii HH103-Rif ${ }^{r}$ or SVQ561. The bacterial population sizes were estimated by plate counting 10 days after inoculation.

Plant test and microscopy studies aimed at determining the formation of nodule primordia in $V$. unguiculata roots were carried out as previously described (López-Lara et al. 1995; van Brussel et al. 2002).

\section{ACKNOWLEDGMENTS}

This work was supported by the Spanish Ministry of Science and Technology (BIO2005-08691-C02 and AGL2006-13758-C05-04). D. P. Sutton's studentship was supported by the EPSRC and the European Union (ICA4CT-2001-10056), and J. E. Thomas-Oates gratefully acknowledges funding from the Analytical Chemistry Trust Fund, the RSC Analytical Division, and EPSRC.

\section{LITERATURE CITED}

Amemura, A., and Cabrera-Crespo, J. 1986. Extracellular and low-M polysaccharides containing $(1,2)-\beta$-D-glucosidic linkages from strains of Xanthomonas, Escherichia coli and Klebsiella pneumonie. J. Gen. Microbiol. 132:2443-2452.

Arellano-Reynoso, B., Lapaque, N., Salcedo, S., Briones, G., Ciocchini, A. E., Ugalde, R., Moreno, E., Morrión, I., and Gorvel, J.P. 2005. Cyclic beta-1,2-glucan is a Brucella virulence factor required for intracellular survival. Nat. Immunol. 6:618-625.

Batley, M., Redmond, J. W., Djordjevic, S. P., and Rolfe, B. G. 1987. Characterisation of glycerophosphorylated cyclic $\beta$-1,2-glucans from a fast-growing Rhizobium species. Biochem. Biophys. Acta 901:119-126.

Becker, A., and Pühler, A. 1998. Production of exopolysaccharides. Pages 97-118 in: The Rhizobiaceae. Molecular Biology of Model Plant-Associated Bacteria. H. P. Spaink, A. Kondorosi, and P: J. J. Hooykaas, eds. Kluwer Academic Publisher, Dordrecht, The Netherlands.

Becker, A., Küster, H., Niehaus, K., and Pühler, A. 1995a. Extension of the Rhizobium meliloti succinoglycan biosynthesis gene cluster: Identification of the exsA gene encoding an $\mathrm{ABC}$ transporter protein, and the $\operatorname{exs} B$ gene which probably codes for a regulator of succinoglycan biosynthesis. Mol. Gen. Genet. 249:487-497.

Becker, A., Schmidt, M., Jäger, W., and Pühler, A. 1995b. New gentamicinresistance and $l a c Z$ promoter-probe cassettes suitable for insertion mutagenesis and generation of transcriptional fusions. Gene 162:37-39.

Beringer, J. E. 1974. R factor transfer in Rhizobium leguminosarum. J. Gen. Microbiol. 84:188-198.

Bhagwat, A. A., and Keister, D. L. 1995. Site directed mutagenesis of the $\alpha(1>3), \alpha(1>6)$-D-glucan synthesis locus of Bradyrhizobium japonicum. Mol. Plant-Microbe Interact. 8:366-370.

Bhagwat, A. A., Tully, R. E., and Keister, D. L. 1992. Isolation and characterization of an $n d v B$ locus from Rhizobium fredii. Mol. Microbiol. 6:2159-2165

Breedveld, M. W., and Miller, K. J. 1994. Cyclic $\beta$-glucans of members of the family Rhizobiaceae. Microbiol. Rev. 58:145-161.

Breedveld, M. W., and Miller, K. J. 1998. Cell-surface $\beta$-glucans. Pages 81-96 in: The Rhizobiaceae. Molecular Biology of Model Plant-Associated Bacteria. H. P. Spaink, A. Kondorosi, and P. J. J. Hooykaas, eds. Kluwer Academic Publisher, Dordrecht, The Netherlands.

Breedveld, M. W., Zevenhuizen, L. P., and Zehnder, A. J. 1990. Excessive excretion of cyclic beta-(1,2)-glucan by Rhizobium trifolii TA-1. Appl. Environ. Microbiol. 56:2080-2086.

Breedveld, M. W., Benesi, A. J., Marco, M. L., and Miller, K. J. 1995. Effect of phosphate limitation on synthesis of periplasmic cyclic (beta)(1,2)-glucans. Appl. Environ. Microbiol. 61:1045-1053.

Buendía-Clavería, A. M., Chamber, M., and Ruiz-Sainz, J. E. 1989. A comparative study of the physiological characteristics, plasmid content and symbiotic properties of different Rhizobium fredii strains. Syst. Appl. Microbiol. 12:203-209.

Buendía-Clavería, A. M., Moussaid, A., Ollero, F. J., Vinardell, J. M., Torres, A., Moreno, J., Gil-Serrano, A. M., Rodríguez-Carvajal, M. A., Tejero-Mateo, P., Peart, J. L., Brewin, N. J., and Ruiz-Sainz, J. E. 2003. A purL mutant of Sinorhizobium fredii $\mathrm{HH} 103$ is symbiotically defective and altered in its lipopolysaccharide. Microbiology 149:1807-1818.

Ciucanu, I., and Costello, C. E. 2003. Elimination of oxidative degradation during the per-O-methylation of carbohydrates. J. Am. Chem. Soc. 125:16213-16219.

Crespo-Rivas, J. C., Margaret, I., Pérez-Montaño, F., López-Baena, F. J., Vinardell, J. M., Ollero, F. J., Moreno, J., Ruiz-Sainz, J. E., and Buendía-Clavería, A. M. 2007. A pyrF auxothrophic mutant of Sinorhizobium fredii HH103 impaired in its symbiotic interactions with soybean and other legumes. Int. Microbiol. 10:169-176.

D'Antuono, A. L., Casabuono, A., Couto, A., Ugalde, R. A., and Lepek, V. C. 2005. Nodule development induced by Mesorhizobium loti mutant strains affected in polysaccharide synthesis. Mol. Plant-Microbe Interact. 18:446-457. 
D’Antuono, A. L., Ott, T., Krussel, L., Voroshilova, V., Ugalde, R. A., Udvardi, M., and Lepek, V. C. 2008. Defects in rhizobial cyclic glucan and lipopolysaccharide synthesis alter legume gene expresion during nodule development. Mol. Plant-Microbe Interact. 21:50-60.

Dickstein, R., Bisseling, T., Reinhold, V. N., and Ausubel, F. M. 1988. Expression of nodule-specific genes in alfalfa root nodules blocked at an early stage of nodule development. Genes Dev. 2:677-687.

Dowdle, S. F., and Bohlool, B. B. 1985. Predominance of fast-growing Rhizobium japonicum in a soybean field in the People's Republic of China. Appl. Environ. Microbiol. 50:1171-1176.

Dylan T., Helinski, D. R., and Ditta, G. 1990a. Hypoosmotic adaptation in Rhizobium meliloti requires $\beta$-(1,2)-glucan. J. Bacteriol. 172:14001408.

Dylan, T., Nagpal, P., Helinski, D. R., and Ditta G. S. 1990b. Symbiotic pseudorevertants of Rhizobium ndv mutants. J. Bacteriol. 172:14091417.

Fraysse, N., Couderc, F., and Poinsot, V. 2003. Surface polysaccharide in volvement in establishing the Rhizobium-legume symbiosis. Eur. J. Biochem. 270:1365-1380.

Gage, D. J. 2004. Infection and invasion of roots by symbiotic, nitrogenfixing rhizobia during nodulation of temperate legumes. Mol. Biol. Rev. $68: 280-300$

Geiger, O, Weissborn, A. C., and Kennedy, E. P. 1991. Biosynthesis and excretion of cyclic glucans by Rhizobium meliloti 1021. J. Bacteriol. 173:3021-3024

Geremia, R. A., Cavaignac, A., Zorreguieta, A., Toro, N., Olivares, J., and Ugalde, R. A. 1987. A Rhizobium meliloti mutant that forms ineffective pseudonodules in alfalfa produces exopolysaccharides but fails to form $\beta$-(1,2)-glucan. J. Bacteriol. 169:880-884

Gerwig, G. J., Kamerling, J. P., and Vliegenthart, J. F. G. 1978. Determination of $\mathrm{D}$ and L configuration of neutral monosaccharides by high-resolution capillary g.l.c. Carbohydr. Res. 62:349-357.

Gil-Serrano, A. M., Franco-Rodriguez, G., Gonzalez-Jiménez, I., TejeroMateo, P., Molina, J. M., Dobado, J. A., Megias, M., and Romero, M. J. 1993. The structure and molecular mechanics calculations of the cyclic (1-2)- $\beta$-D-glucan secreted by Rhizobium tropici CIAT 899. J. Mol. Struct. 301:211-226.

Gil-Serrano, A. M., Rodríguez-Carvajal, M. A., Tejero-Mateo, P., Espartero, J. L., Thomas-Oates, J., Ruiz-Sainz, J. E., and Buendía-Clavería, A. M. 1998. Structural determination of a 5-O-methyl-deaminated neuraminic acid (Kdn)-containing polysaccharide isolated from Sinorhizobium fredii. Biochem. J. 334:585-594.

Gil-Serrano, A. M., Rodríguez-Carvajal, M. A., Tejero-Mateo, P., Espartero J. L., Menéndez, M., Corzo, J., Ruiz-Sainz, J. E., and Buendía-Clavería, A. M. 1999. Structural determination of a 5-acetamido-3,5,7,9-tetradeoxy-7-(3-hydroxybutyramido)-L-glycero-L-manno-nonulosonic acidcontaining homopolysaccharide isolated from Sinorhizobium fredii HH103. Biochem. J. 342:527-535.

Granath, K. A., and Kvist, B. E. 1967. Molecular weight distribution analysis by gel chromatography on Sephadex. J. Chromatogr. 280:69-81.

Inon de Iannino, N., and Ugalde, R. A. 1993. Biosynthesis of cyclic beta(1-3), beta-(1-6) glucan in Bradyrhizobium spp. Arch. Microbiol. 159:30-38.

Inon de Iannino, N., Briones, G., Kreiman, G., and Ugalde, R. 1996. Characterization of the biosíntesis of $\beta(1-2)$ cyclic glucan in $R$. fredii. $\beta(1-2)$ glucan has no apparent role in nodule invasion of McCall and Peking soybean cultivars. Cell. Mol. Biol. 42:617-629.

Jones, K. M., Kobayashi, H., Davies, B. W., Taga, M. E., and Walker, G C. 2007. How rhizobial symbionts invade plants: The SinorhizobiumMedicago model. Nature 5:619-633.

Kim, J. S., Reuhs, B. L., Michon, F., Kaiser; R. E., and Arumugham, R. G. 2006. Addition of glycerol for improved methylation linkage analysis of polysaccharides. Carbohydr. Res. 341:1061-1064.

Ko, Y. H., and Gayda, R. 1990. Nodule formation in soybeans by exoplysaccharide mutants of Rhizobium fredii USDA191. J. Gen. Microbiol. 136:105-113.

Lamrabet, Y., Bellogín, R. A., Cubo, T., Espuny, R., Gil, A., Krishnan, H. B., Megias, M., Ollero, F. J., Pueppke, S. G., Ruiz-Sainz, J. E., Spaink, H. P., Tejero-Mateo, P., Thomas-Oates, J., and Vinardell, J. M. 1999. Mutation in GDP-Fucose synthesis genes of Sinorhizobium fredii alters Nod factors and significantly decreases competitiveness to nodulate soybeans. Mol. Plant-Microbe Interact. 12:207-217.

López-Lara, I. M., van Der Drift, K. M. G. M., van Brussel, A. A. N.,
Haverkamp, J., Lugtenberg, B. J. J., Thomas-Oates, J., and Spaink, H. P. 1995. Induction of nodule primordia on Phaseolus and Acacia by lipo-chitin oligosaccharide nodulation signals from broad-host-range Rhizobium strain GRH2. Plant Mol. Biol. 29:465-477.

Mathis, R., van Gijsegem, F., De Ryche, R., D'Haeze, W., Van Maelsaeke, E. Antonio, E., van Montagu, M., Holsters, M., and Vereecke, D. 2005. Lipopolysaccharides as a communication signal for progression of legume endosymbionts. Proc. Natl. Acad. Sci. U.S.A. 102:2655-2660.

Nagpal, P., Khanuja, S. P., and Stanfield, S. W. 1992. Suppression of the ndv mutant phenotype of Rhizobium meliloti by cloned exo genes. Mol. Microbiol. 6:479-488.

Parada, M., Vinardell, J. M., Ollero, F. J., Hidalgo, A., Guitiérrez, R., Buendía-Clavería, A. M., Lei, W., Margaret, I., López-Baena, F. J., GilSerrano, A. M., Rodríguez-Carvajal, M. A., Moreno, J., and Ruiz-Sainz, J. E. 2006. Sinorhizobium fredii HH103 mutants affected in capsular polysaccharide (KPS) are impaired for nodulation with soybean and Cajanus cajan. Mol. Plant-Microbe Interact. 19:43-52.

Prentki, P., and Krisch, H. M. 1984. In vitro insertional mutagenesis with a selectable DNA fragment. Gene 29:303-313.

Rigano, L. A., Payette, C., Brouillard, G., Marano, M. R., Abramowicz, L. Torres, P. S., Yun, M., Castagnaro, A. P., El Oirdi, M., Dufour, V. Malamud, F., Dow, J. M., Bouarab, K., and Vojnov, A. A. 2007. Bacterial cyclic $\beta-(1,2)$-glucan acts in systemic suppression of plant immune responses. Plant Cell 19:2077-2089.

Sambrook, J., Fritsch, E. F., and Maniatis, T. 1989. Molecular Cloning. A Laboratory Manual, 2nd ed. Cold Spring Harbor Laboratory Press, Cold Spring Harbor, NY, U.S.A.

Schafer, A., Tauch, A., Jager, W., Kalinowski, J., Thierbach, G., and Puhler, A. 1994. Small mobilizable multi-purpose cloning vectors derived from the Escherichia coli plasmids pK18 and pK19: Selection of defined deletions in the chromosome of Corynebacterium glutamicum. Gene 145:69-73.

Simon, R. 1984. High frequency mobilization of gram-negative bacterial replicons by the in vivo constructed Tn5-Mob transposon. Mol. Gen. Genet. 196:413-420.

Spaink, H. P., Okker, R. J., Wijffelman, C. A., Pees, E., and Lugtenberg, B. J. J. 1987. Promoters in nodulation region of the Rhizobium legumino sarum Sym plasmid pRL1JI. Plant Mol. Biol. 9:27-39.

Stanfield, S. W., Ielpi, L., O'Brochta, D., Helinski, D. R., and Ditta, G. S. 1988. The $n d v A$ gene product of Rhizobium meliloti is required for beta(1----2)glucan production and has homology to the ATP-binding export protein HlyB. J. Bacteriol. 170:1523-1530.

Ugalde, R. A. 1999. Intracellular lifestyle of Brucella spp. common genes with other animal pathogens, plant pathogens, and endosymbionts. Microbes Infect. 1:1211-1219.

van Brussel, A. A. N., Tak, T., Boot, K. J. M., and Kijne, J. W. 2002. Autoregulation of root nodule formation: Signals of both symbiotic partners studied in a split-root system of Vicia sativa subsp. nigra. Mol. PlantMicrobe Interact. 15:341-349.

Vinardell, J. M., López-Baena, F. J., Hidalgo, A., Ollero, F. J., Bellogín, R., Espuny, M. R., Temprano, F., Romero, F., Krishnan, H. B., Pueppke, S. G., and Ruiz-Sainz J. E. 2004a. The effect of FITA mutations on the symbiotic properties of Sinorhizobium fredii varies in a chromosomalbackground-dependent manner. Arch. Microbiol. 181:144-154.

Vinardell, J. M., Ollero, F. J., Hidalgo, A., López-Baena, F. J., Medina, C., Ivanov-Vangelov, K., Parada, M., Madinabeitia, N., Espuny, M. R.., Bellogín, R. A., Camacho, M., Rodríguez-Navarro, D. N., Soria-Díaz, M. E., Gil-Serrano, A. M., and Ruiz-Sainz, J. E. 2004b. NolR regulates diverse symbiotic signals of Sinorhizobium fredii HH103. Mol. PlantMicrobe Interact. 17:676-685.

Vincent, J. M. 1970. Appendix III. The modified Fåhraeus slide technique. Pages 144-145 in: A Manual for the Practical Study of Root Nodule Bacteria. J. M. Vincent, ed. Blackwell Scientific Publications, Oxford.

Westphal, O., and Jann, K. 1965. Bacterial lipopolysaccharides, extraction with phenol-water and further application of the procedure. Methods Carbohydr. Chem. 5:83-91.

\section{AUTHOR-RECOMMENDED INTERNET RESOURCES}

GeneFisher2 utility: bibiserv.techfak.uni-bielefeld.de/genefisher2 ORF-Finder: www.ncbi.nlm.nih.gov/gorf/gorf.html

BLAST: www.ncbi.nlm.nih.gov/BLAST 